\title{
Effect of Buttress Form on Transverse Seismic Resistance of High Masonry Walls
}

\section{Arif Gürel}

Harran University: Harran Universitesi

Rabia İzol ( $\nabla$ rabiaizol@harran.edu.tr)

Harran University: Harran Universitesi https://orcid.org/0000-0002-7568-3817

\section{Çağrı Mollamahmutoğlu}

Yıldız Teknik Üniversitesi: Yildiz Teknik Universitesi

\section{R. Kadir Pekgökgöz}

Harran University: Harran Universitesi

F. Şebnem Kuloğlu Yüksel

Harran University: Harran Universitesi

Meryem Özeren

Harran University: Harran Universitesi

\section{Research Article}

Keywords: Historic masonry structures, High walls, Buttress form, Transverse seismic resistance, Nonlinear static analyis, Abaqus

Posted Date: March 5th, 2021

DOI: https://doi.org/10.21203/rs.3.rs-233787/v1

License: (c) (1) This work is licensed under a Creative Commons Attribution 4.0 International License.

Read Full License 


\title{
Effect of buttress form on transverse seismic resistance of high masonry walls
}

\author{
M. Arif Gürel ${ }^{1}$, Rabia İzol ${ }^{1}$, Çağrı Mollamahmutoğlu ${ }^{2}$, R. Kadir Pekgökgöz1 \\ F. Şebnem Kuloğlu Yüksel ${ }^{3}$, and Meryem Özeren ${ }^{4}$ \\ ${ }^{1}$ Harran University, Department of Civil Engineering, Şanlıurfa, Turkey \\ ${ }^{2}$ Y1ldız Technical University, Department of Civil Engineering, İstanbul, Turkey \\ ${ }^{3}$ Harran University, Department of Architecture, Şanlıurfa, Turkey \\ ${ }^{4}$ Antalya Foundations Regional Directorate, Antalya, Turkey
}

Corresponding author:

Rabia İzol

rabiaizol@harran.edu.tr 


\begin{abstract}
In historical masonry structures having vault, dome and high walls, for safety against gravity, wind and earthquake loads, buttresses are crucial elements. This study aims to investigate the effect of buttress form on the transverse seismic resistance of high masonry walls. For this purpose, a real historical masonry structure covered by a barrel vault, and has a simple and regular plan and elevation shape was considered. From a slice of this structure, a calculation model and a basic model were created. For the masonry, macro-modelling approach was used. Nonlinear static analysis method was adopted, and finite element modeling and calculations were carried out using the Abaqus program. Firstly, on the calculation model the effect of buttress depth on transverse seismic resistance was investigated, and it was seen that the resistance is almost linearly related to the buttress depth. Then, two groups of analyses were performed on the models obtained by mounting different buttress forms to the basic model. In the first group, the volumes of the buttresses were kept equal, and in the second group their base depths and thicknesses were taken equally. At the end of these analyses, by comparing the base shear forces obtained for the models, the effectiveness of buttress form on the transverse seismic resistance has been determined and evaluated. The results revealed that the model with curvilinear concave buttresses in the first group analyses and the model with semi-cylindrical buttresses in the second group analyses have the highest seismic resistance.
\end{abstract}

\title{
Keywords
}

Historic masonry structures; High walls; Buttress form; Transverse seismic resistance; Nonlinear static analyis, Abaqus.

\section{Introduction}

The components of building type historical masonry structures are vaults, domes, arches, piers, pillars, walls, buttresses and foundatios. Buttresses are crucial elements to support the walls against the thrust forces transmitted from the vaults, domes and arches. The buttresses are also necessary to provide adequate safety to the structures against wind and earthquake forces. When we look at great 
mosques, cathedrals, castles, caravanserais, missions etc, we see that high walls of these structures had been propped by buttresses almost every time. This shows indisputably that ancient builders were well aware of the importance of buttresses. This is also evident from the fact that most historical building design rules that have survived today mention intensively about the buttress design (Huerta, 2010).

This study deals with the effect of buttress form on the transverse (perpendicular to longitudinal direction) seismic resistance of high masonry walls which are frequently encountered in building type historic masonry structures. In the second section buttress forms encountered in historical structures reviewed. Third section gives a literature review about the works on masonry buttresses. In the fourth section which forms the main body of the study, the method is given, and by considering different buttress forms, transverse seismic resistance of a real historical masonry structure is investigated. In this section, the results obtained are also discussed. After presenting the conclusions in the fifth section, the study is finished with references.

\section{Buttress types in historic masonry structures}

Besides some secondary factors such as maintenance, restoration and strengthening, many historical masonry structures have reached present day from the past, thanks primarily to the wisdom, deep foresight and experience of ancient builders. These structures are living examples of correct understanding of the structural behavior by their builders. It can be said that the buttresses are one of the principal indicators of this correct understanding.

To the authors' knowledge, there is no precise information about when and where the buttress was used for the first time. However, it can be seen from many scientific studies that the buttress was used in many buildings in Mesopotamia, the cradle of the oldest civilizations. Over time, the buttress was used in various structures of all civilizations.

There are close definitions for the "buttress" in the literature. Based on these definitions and its function, the buttress can be defined simply as "a projection built up against a wall or a structure, 
to form additional strength or furnish support", (Smith, 1880). Buttresses have been used in almost all building type structures, castles, dams, bridges, retaining walls, etc. in the past.

It is seen that in most of the historical structures, buttresses are original, i.e. they had been built together with the walls of the structure. However, in some cases, it is understood from historical documents and/or on-site inspections that they were added to the structure later. The famous Hagia Sophia in İstanbul, whose some buttresses were added later by the great Ottoman architect "Mimar Sinan", can be given as an example to these structures.

It is observed that the buttresses had been positioned in three ways with respect to the walls in the building type historical masonry structures. On the outer face of the wall, which is the most common situation, on the inner face and, some part on the outer face and the other on the inner. In the vast majority of structures, these buttresses are perpendicular to the walls. But, for the corners of intersecting walls, there are also examples where the buttresses had been settled diagonally.

When investigated it is seen that, in historical masonry structures there are a wide variety of forms for the buttresses. In choosing of buttress form, builders may have considered the following factors: i) requests of building owners, ii) aesthetics, iii) construction simplicity, iv) height of construction, v) tradition, vi) climate conditions, vii) seismicity and viii) wind effect.

Figure 1 presents some buttress examples from historical architecture. Buttresses which have simple rectangular, trapezoidal, and triangular profile shape are the most common types. Stepped rectangular buttresses are also very common. Combined buttresses consisting of several parts such as rectangle and trapezoid or rectangle and triangle are also common. Curvilinear ones (parabolic or other) are less common. On the other hand, there are also some buttresses which are really rare and interesting. Semi-cylindrical, half-conic, lobed, triangular prism, triangular pyramid (tetrahedron), hollow cyclindrical and hollow triangular prism shaped buttresses can be given as examples to this kind of buttresses. And, flying buttress is a very privileged type. Of course, there are also certainly other, local and very specific, buttress types in the world's vast historical architecture. 


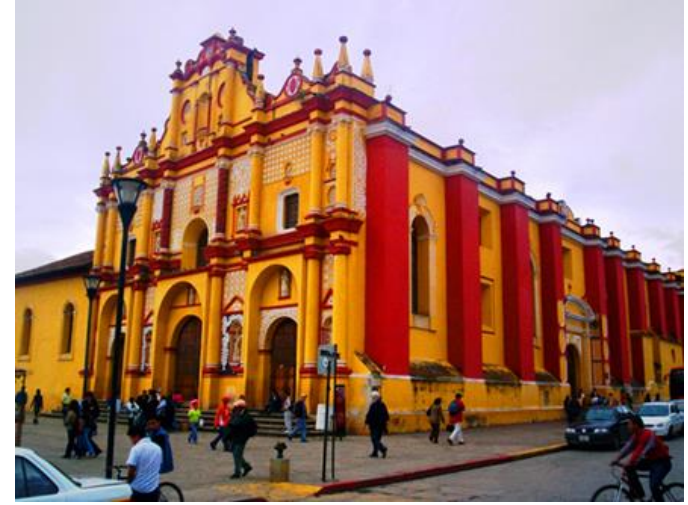

a) Rectangular buttresses of San Cristobal Cathedral, (Las Casas, Mexico), (Url-1)

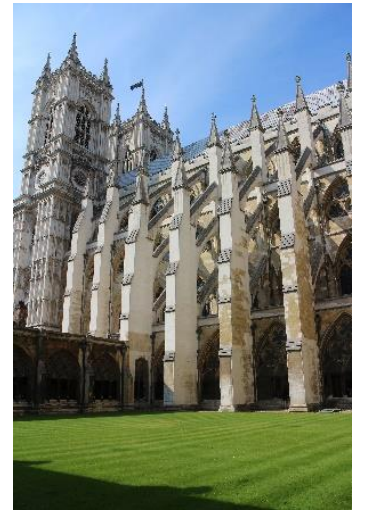

c) Stepped buttresses of Westminster Abbey, (London, England), (Url-2)

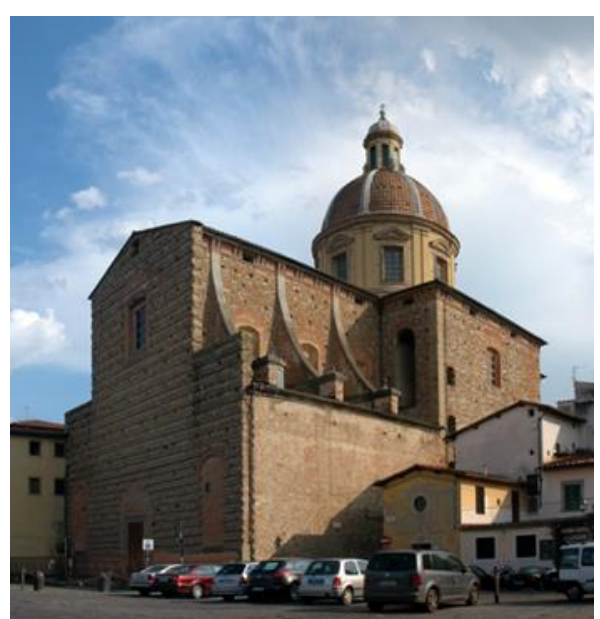

e) Curvilinear buttresses of San Frediano Church, (Florence, Italy), (Url-3)

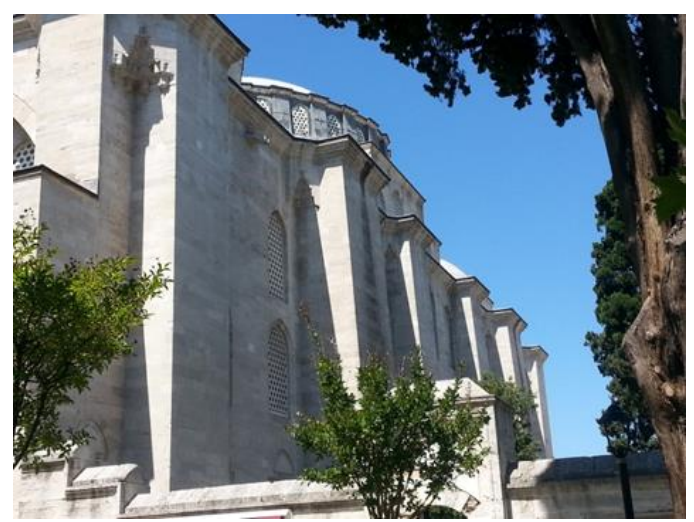

b) Trapezoidal buttresses of Qibla wall of Süleymaniye Mosque (İstanbul, Turkey), (Photo: Authors)

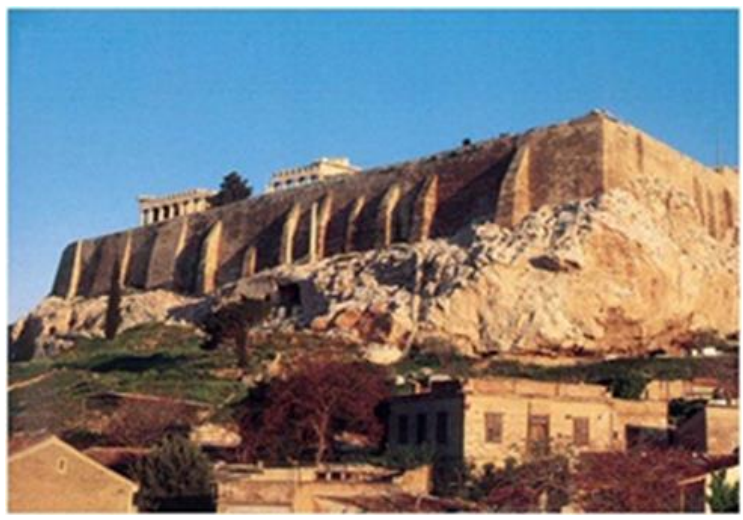

d) Combined buttresses of retaining walls of Acropolis of Athens, (Athens, Greece), (Stierlin, 1997)

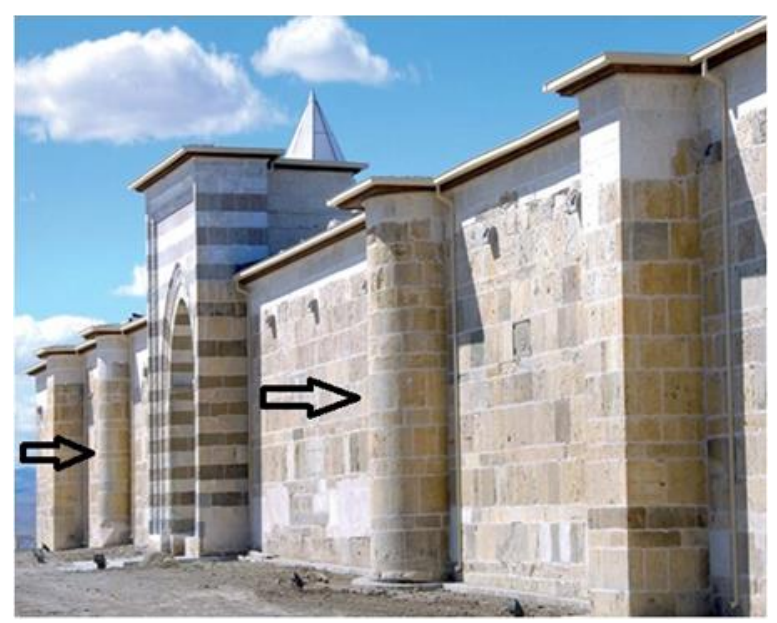

f) Semi-circular buttresses of Zazadin Han (Inn), (Konya, Turkey), (Url-4)

Fig. 1 Buttress examples from historical masonry architecture 


\section{Previous works on masonry buttresses}

Because of their primary role for the safety of most of the building type historical masonry structures, various investigations have been carried out in the past on sizing, behaviour, capacity and collapse of masonry buttresses. In this section, summaries of a good part of these studies are presented briefly.

By making a concise interpretation of successful material minimalism in Gothic architecture, Bartholomew (1840), with a leaning human posture model, explained the association of the flying buttress, the pinnacle and the external buttress trio in supporting the structure, Fig. 2.

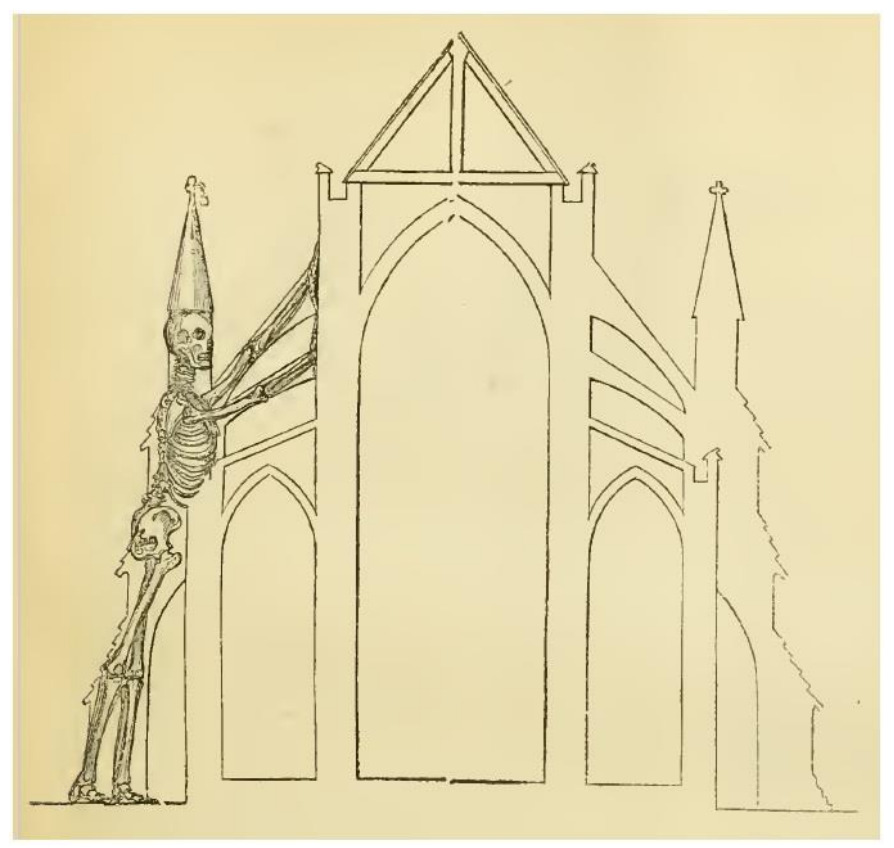

Fig. 2 A leaning human model representing the cooperation of flying buttress, pinnacle and external buttress trio in supporting a Gothic cathedral, Bartholomew, (1840)

Ungewitter and Mohrmann $(1890,1892)$ wrote a very detailed two-volume book on the construction and behavior of Gothic cathedrals. They used generally graphic static analysis techniques and gave a wide coverage to both classical and flying buttresses. It can be definitely said that, the book is one of the most comprehensive works that deals with the buttresses in such detail. 
Sanabria (1982) engaged in the mechanization of structural design in the 16th century. He commentated on the Spanish architect Rodrigo Gil de Hontãnón's 16th century master masons' formulas concerned with the safe dimensioning of buttresses.

Mark (1984) in his fascinating book investigated the structural elements of Gothic cathedrals. He used the photoelastic modeling technique of structural mechanics to solve historical arguments such as whether the flying buttresses hold the roof or are simply decorative, the ornate pinnacles on the buttresses are structurally necessary or completely aesthetic, and whether the ribs of the vaults hold the ceiling, (Url-5).

In his $\mathrm{PhD}$ thesis (1990) and in his another work (2004) Huerta gives vast information about the sizing rules of buttresses during the medieval and Renaissance eras. It is understood clearly from the Huerta's these two precious works that the ancient builders had a rather high level of awareness about the importance of buttresses for the safety of the whole structure.

In his famous book “The Stone Skeleton: Structural Engineering of Masonry Architecture”, Heyman (1995) provides a comprehensive and at the same time intuitive understanding especially of historical masonry structures. In this respect, he also explained the behavior of some structural elements, including flying buttresses, and gave knowledge with various examples.

Ochsendorf et al. (2004) investigated the collapse of masonry buttresses under concentrated lateral loads. They determined that, a fracture forms at the collapse state and this decreases the overturning resistance of buttress significantly. And therefore, they pointed out that, the conventional analysis which assumes that a masonry buttress acts monolithically to resist lateral loads is unsafe, and the possibility of a fracture at the collapse state must be considered in the design and assessment of masonry buttresses.

Ochsendorf and De Lorenzis (2008) considering a number of parameters, such as sliding, finite compressive strength and leaning, investigated the collapse condition of rectangular masonry buttresses subjected to a concentrated inclined load.

García and Meli (2009) aimed at to find out whether the 16th century Mexican convent church builders followed structural rules stated in the building treatises from that period, when 
dimensioning the structural elements, especially the walls and buttresses which counteract the thrust of the vaults.

Huerta (2010) performed a comprehensive investigation on the safety of masonry buttresses. Within this context, he outlined the development of buttress design since the 16th century, and explained the main approaches used. In the study, the effect of the buttress form in terms of stability against overturning is also briefly examined.

De Lorenzis et al. (2010a, 2010b) in their two companion studies, taking into account fracturing prior to overturning and possible sliding, carried out detailed collapse analyses of trapezoidal and stepped masonry buttresses.

Makris and Alexakis (2015) studied on the fracturing of rectangular masonry buttresses and towers when subjected either to a concentrated oblique force at their head or to lateral inertial loading due to earthquake ground motion. For the inertial loading, the equivalent static analysis procedure was adopted, and a uniform and an inverted triangular load distribution were considered.

Karimi et al. (2016), through library studies and, descriptive and analytical research method, investigated the typology and developments of buttresses in Iranian architecture. They examined 32 archaeological sites from prehistoric and historical periods. The buttresses in these sites were examined and recorded in terms of their features such as position, form, material, technical function and ornamentation. They came to the conclusion that, with the increase of architects' awareness about the structural importance of buttresses over time, they had emphasized more and more the technical aspect of this element in their structures.

Fuentes (2018) after accurately surveying the Mallorca cathedral, she used the theoretical framework of limit analysis to analyse the distortion and sliding movements observed at some flying buttresses of the cathedral. It was concluded from the study that, flying buttresses have a fundamental role in the stability of the structure, although some of them experienced various problems over time.

Chávez and Peña (2019) investigated the influence of the thickness of vaults and buttresses in the structural response of Mexican Colonial Temples. For this purpose, they performed a parametric analysis on the prototype of a typical temple. 
Izol et al. (2019) using an existing numerical calculation model and adopting equivalent static analysis procedure, investigated the out-of-plane seismic resistance of high masonry walls having rectangular buttresses.

In addition to above-referred works, it is seen that some other articles and conference proceedings on historical masonry structures have given wide coverage to the buttresses in those structures. For example, in their study about the possible influences of the construction stage and long-term deformations on the current state of the Mallorca Cathedral, Roca et al. (2013) laid emphasis on both classical and flying buttresses of the structure. To give another example, Karanikoloudis et al. (2020) gave considerable place to the buttresses in their work about Canterbury Cathedral. Similarly, in many valuable books on historical masonry structures, the buttresses also of the structures are naturally mentioned. John Freely's "A History of Ottoman Architecture" and Charles Herbert Moore's "Development and Character of Gothic Architecture" are only two examples.

Above, studies about both classical wall buttresses and flying buttresses were given. All of them are very precious works. As for the present study, this is about the classical buttresses. Of the studies cited, those related to the classical buttresses and being analytical, except García and Meli (2009), Makris and Alexakis (2015), Chávez and Peña (2019), and İzol et al. (2019), have in general to the feature of analyzing the buttresses under a single static oblique force. However, the walls of structures being located in earthquake regions and containing vaults, domes or arches, are subject not only to this oblique force transmitted from the mentioned elements, but also to earthquake forces, in case of an earthquake. An enormous scientific literature has been created on the earthquake behavior and resistance of historic masonry structures and the studies are continuing. Nevertheless, there is few work related to earthquake resistance of walls having classical buttresses. Despite the surprising diversity of the buttresses in historic masonry structures, no study investigating the effects of the buttress form on the transverse seismic resistance of masonry walls has been found in the literature. This situation has been the main motivation point of the present study.

This study investigates the transverse seismic resistance of high masonry walls in case of they having various buttress forms such as rectangular, trapezoidal, stepped, combined, curvilinear or semi-cylindrical. In this way, the effects of buttress form on the transverse seismic resistance of the 
walls will be determined. Since the flying buttress is not a classical wall buttress, it is not included in the investigation.

\section{Considered structure and buttress forms, the method, and the analyses}

This section forms the main body of the study. In line with the purpose, all analyses are made in this section and the findings obtained from them are discussed here.

\subsection{Introduction of the structure and its calculation model}

In this study, it is intended to make analyses on the models of a real, i.e. existing historical masonry structure. The structure considered is Şarapsa Han (Inn) in Alanya (Antalya, Turkey), Fig. 3. It is a stone masonry structure and involves most of the features suitable for the purpose of the study. These features are that; it is a building-type historical masonry structure, it has a simple and regular plan and transverse section shape, has long walls supported by buttresses placed at fairly equal intervals, and its cover is a vault.

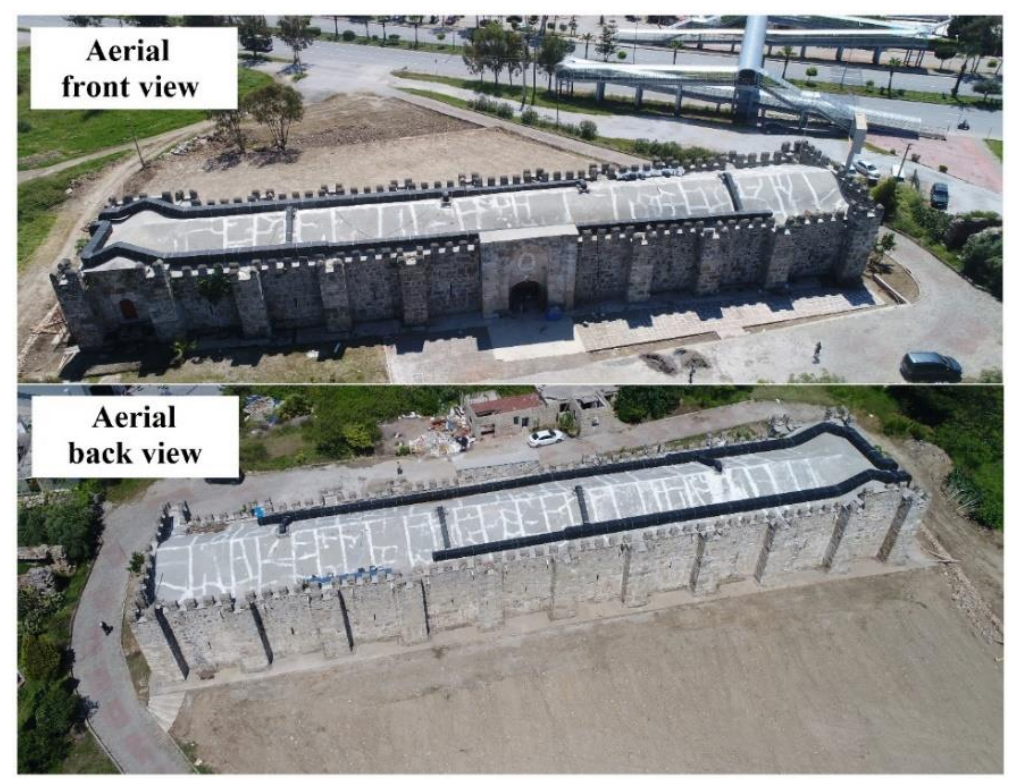

Fig. 3 Şarapsa Han, (Photo: Authors) 
The Han is consists only of an accommodation part and a masjid (small mosque), Fig. 4. Each part was covered with an arched barrel vault and these vaults are perpendicular to each other. North and south walls of the building are supported by rectangular prismatic buttresses that are arranged almost at equal intervals and rise to the roof level. The Han was built on a sloping ground. Natural ground level under the south wall is approximately $70 \mathrm{~cm}$ below that of the north wall.

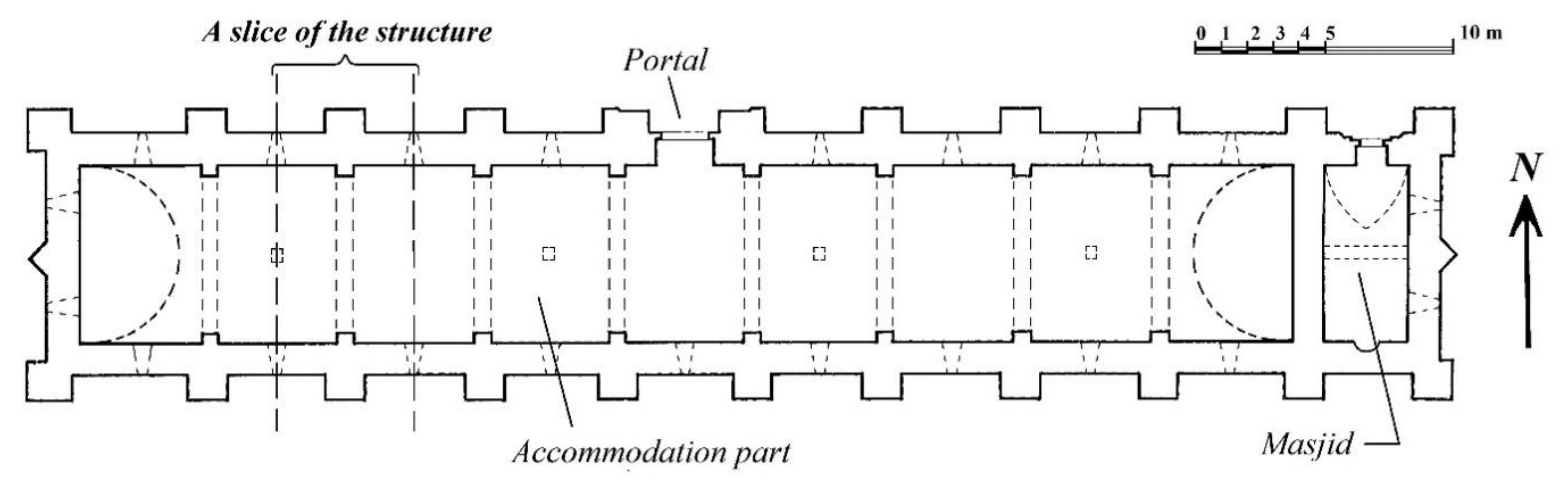

Fig. 4 Plan of the Şarapsa Han (Used with the permission of Antalya Foundations Regional Directorate)

The structure has approximately $72 \mathrm{~m} \times 15 \mathrm{~m}$ plan dimensions from out-to-out. Inner width of the accommodation part is $8.90 \mathrm{~m}$ at the east end and $8.93 \mathrm{~m}$ at the west end. The length (dimension in the longitudinal direction) and width (dimension in the transverse direction) of each bay between the vault arches are $7.00 \mathrm{~m}$ and $8.915 \mathrm{~m}$, on average, respectively. In this part, the thicknesses of the south, north and west walls are equal and is $1.70 \mathrm{~m}$, and that of the east wall is $1.55 \mathrm{~m}$. There are 22 rectangular buttresses in the structure. Their thicknesses (dimensions parallel to the wall) are between $2.00 \mathrm{~m}$ and $2.47 \mathrm{~m}$, and the average value is $2.20 \mathrm{~m}$. Depths (dimensions perpendicular to the wall) range from $1.26 \mathrm{~m}$ to $1.40 \mathrm{~m}$, with an average of $1.35 \mathrm{~m}$.

The height of the east wall is $5.77 \mathrm{~m}$, the west wall is higher and is $6.93 \mathrm{~m}$. In the accommodation part, the outer face side of the south wall, which is $0.45 \mathrm{~m}$ thick, has a height of 5.85 $\mathrm{m}$, which is equal to the height of the buttresses on this wall. The south wall has $5.55 \mathrm{~m}$ height on the inner face side. The wall reaches to a height of $6.75 \mathrm{~m}$ in the masjid part. As for the north wall, in the 
middle part of this wall, the portal of the building is located, Figs. 3 and 4 . The portal has an austere but beautiful structure, and its total height is $6.90 \mathrm{~m}$. Height of the outer face, which has $0.45 \mathrm{~m}$ thickness, of the northern wall, varies in height from $5.18 \mathrm{~m}$ to $5.32 \mathrm{~m}$, and rises to $6.56 \mathrm{~m}$ in the masjid portal. Average height of the outer face of the north wall and the height of the buttresses on this wall is $5.25 \mathrm{~m}$ at the accommodation part of the structure. The north wall has about $4.95 \mathrm{~m}$ height on the inner face side.

Transverse section (transverse elevation) of the structure is also simple, but it is not fully symmetrical because of the different heights of the south and north walls. This feature of the structure can also be seen from the Fig. 5 which shows a transverse section taken from the portal. It can also be seen from the figure that the thickness of the vault increases significantly towards the walls. While the thickness is $0.80 \mathrm{~m}$ at the crown, it is around $3.5 \sim 4$ times of this value on the walls' surface. The widths and depths (thicknesses) of the arches that support the vault from below are $0.95 \mathrm{~m}$ and 0.45 $\mathrm{m}$, on average, respectively.

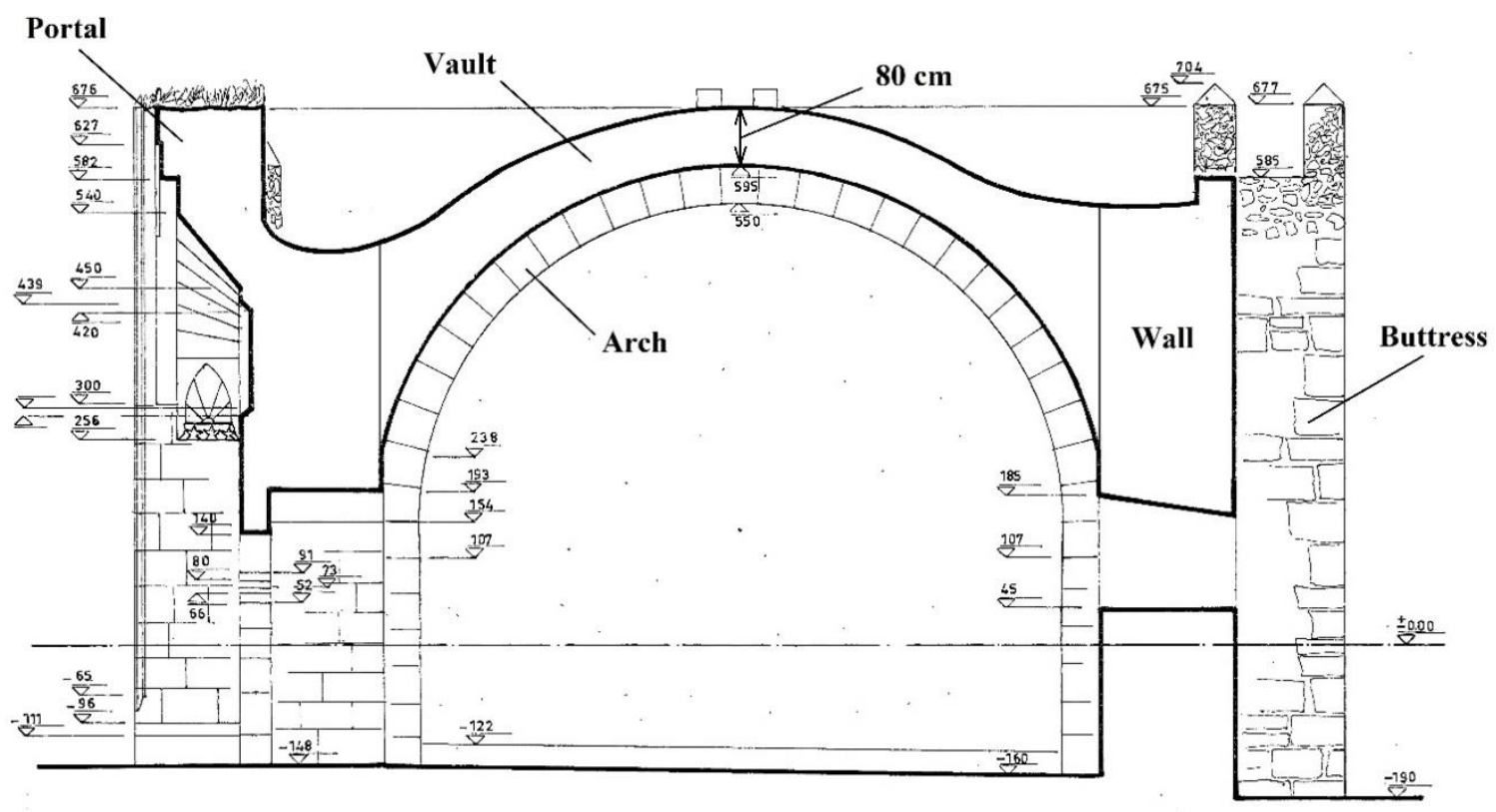

Fig. 5 Transverse section taken from the portal of the Han, (measures are in $\mathrm{cm}$ ), (Used with the permission of Antalya Foundations Regional Directorate) 
Taking advantage of the mentioned regular plan shape and simple transverse section features of the Şarapsa Han, instead of the whole structure, only one slice from the main part (accommodation part) of it can be modeled for analyses. As can be seen from the Fig. 4, this slice consists of the wall portions facing each other among the center lines of two neighbour bays, vault portion connecting them, and two buttresses. The model of the structure, generated on this basis, is given in Fig. 6a.

a)

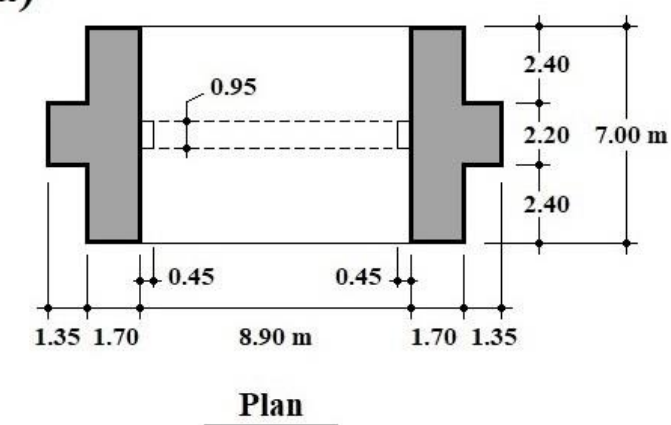

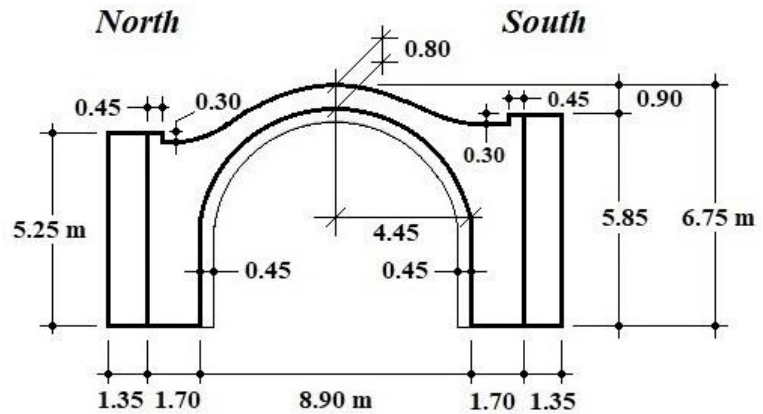

Elevation

b)
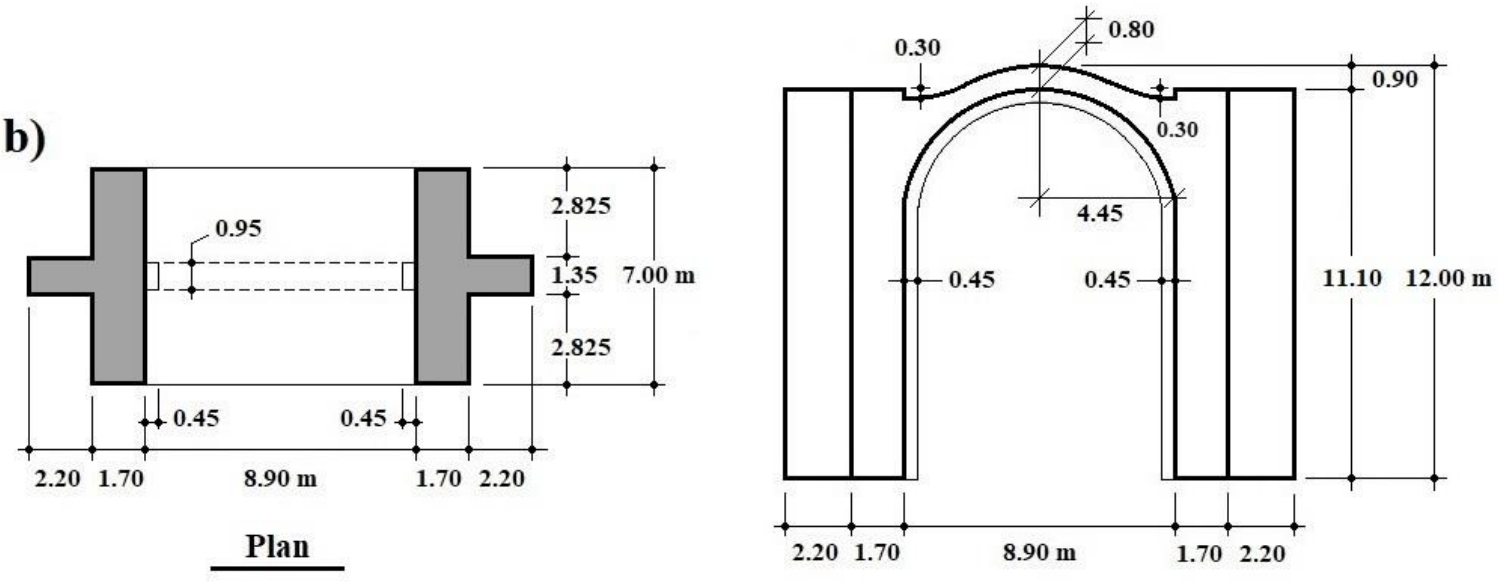

Elevation

Fig. 6 Models of the Şarapsa Han: a) Real model, b) Modified model used in calculations (Drawings are not to scale)

The Han is simple and regular, but its aspect ratio, i.e. height / transverse length ratio, without including the buttresses, is calculated as $6.75 \mathrm{~m} /(8.90+2 \times 1.70) \mathrm{m} \cong 0.55$, Fig. $6 \mathrm{a}-$ elevation. As is known, simply, structures which have aspect ratios less than 1 are called as "squat structure" and 
those with aspect ratios greater than 1 are as "slender structure". Thus, our structure is a squat structure. This is an undesirable feature for the purpose of the study. Because in a squat structure under horizontal loads collapse may occur with shearing (Makris and Alexakis, 2015). This type of collapse is not included within the scope of the present study. The effect of buttress form on transverse seismic resistance of squat masonry structures is being privately investigated by the authors in an ongoing study. Thus, here only the bending collapse case is investigated. Accordingly, the real model of the structure has been modified in three respects to see the effect of the buttress form on the transverse seismic resistance of the high masonry walls. The first modification is that, the height difference between the north and south of the model has been eliminated, and the heights of the wall and buttress on both sides have been equalized. The second change is that, the height has been increased reasonably without exaggeration. The new height value of the buttresses and walls was chosen as twice the average of the original heights of the buttresses. And the third modification has been to rotate the buttresses 90 degrees, to use them around their strong axes. Except for these three changes, all the features of the real model have been left as they are. The model obtained in this way and used in the calculations is shown in Fig. $6 \mathrm{~b}$. The aspect ratio of this model without considering the buttresses is $0.98(\approx 1)$. Thus, although not much, nonetheless a model that can be called as "slender" has been obtained. Hereafter, this model will be called as "calculation model". Of course, as the buttress form changes (triangle, stepped, curvilinear etc.) the buttresses of the model will be in that form.

\subsection{Material properties of the structure, modeling of masonry and assumed material model for}

\section{the analysis}

As for the materials of the Şarapsa Han, it is observed that, although there are also various other stones in the texture of the structure, mostly Isparta stone, which is a local stone, constitutes its body. Mortar used in the structure is Horasan Mortar. This mortar had been used extensively in Byzantine, Seljuk and Ottoman structures. While generally dressed stone had been used in the buttresses of the Han, the walls of it had been built of dressed and roughly shaped stones. The portal, the door wall of 
masjid, and arches of the vaults are from cut stone. In the vaults, generally rubble stone and fill materials had been used.

A literature search has shown that there is no specific work, in-situ testing or other, that deals with the mechanical properties of the materials of the Şarapsa Han. The authors themselves also did not have the opportunity to determine these features of the structure. However, a reliable approximation of material properties can be based on master's thesis of Korkmaz (2019) about historical masonry structures rather similar to that of this study. In his study, Korkmaz (2019) examined various structures such as caravanserai, church and fortress in six ruins from the Hellenistic, Byzantine and Seljuk periods in Isparta and Burdur provinces adjacent to Antalya, which includes the Alanya district where Şarapsa Han is located. Performing both in-situ and laboratory tests, he determined physical, mechanical and thermal properties of stone, brick and mortar materials of the structures in these ruins. Table 1 shows the relevant average values for the stone and mortar materials of his study.

Table 1 Average values of mechanical and physical properties of stone and mortar materials of the historical masonry structures in Korkmaz's (2019) study

\begin{tabular}{cccc}
\hline Material & $\begin{array}{c}\text { Unit weight, } \gamma \\
\left(\mathrm{kN} / \mathrm{m}^{3}\right)\end{array}$ & $\begin{array}{c}\text { Dyn. Modulus of } \\
\text { elasticity, } E(\mathrm{MPa})\end{array}$ & $\begin{array}{c}\text { Compressive strength, } f \\
(\mathrm{MPa})\end{array}$ \\
\hline Stone & 26.37 & 29635 & 79.5 \\
Mortar & 17.95 & 8333 & 11 \\
\hline
\end{tabular}

There is a tremendous literature, that is still expanding, about the behaviour and modelling of masonry structures under static and dynamic loadings. Here, it is not possible and necessary to enter this subject in detail. There are mainly two approaches to model the masonry structures. These are the 'micro-modelling' or 'two-material approach', and the 'macro-modelling' or 'homogenized/equivalentmaterial approach'. In the micro-modelling, the finite element discretization follows the actual geometry of both the units (stone or brick) and mortar joints, adopting different constitutive models for the two components. Whereas, the macro-modelling assumes that the masonry structure is a homogeneous continuum to be discretized with a finite element mesh, which does not copy the wall texture, but complys with the method's own criteria. Aiming to produce results at global level and 
keeping computational work at a manageable degree, this modelling approach finds a middle way between accuracy and simplicity (Illampas et al. (2020), Giordano et al. (2002), and Angelillo (2014)).

In this study, the macro-modelling approach is adopted, and from hence the material of the structure is assumed to be homogeneous. As explained above, Şarapsa Han does not have a texture consisting entirely of dressed stones and with regular joints between them. On the contrary, it is a structure in which irregular texture is dominant, and therefore there is a certain degree of homogeneity and isotropy. Hence, the assumption made for the material of the structure is rational.

In the light of the above explanations, now it should be determined the homogenized material properties of masonry texture of the Şarapsa Han. There are some formulas in the literature for the calculation of the compressive strength and the elastic modulus of the masonry depending on the values of its constituents. Here, the expressions in Tomaževič's book (1999) have been adopted. In this book, which is about the earthquake resistant design of masonry buildings, the following relationship that is based on Eurocode 6, is given to determine the compressive strength of the masonry:

$f_{c}=K f_{S}^{0.65} f_{m}^{0.25} \quad$ (in $\left.\mathrm{MPa}\right)$

in which $K$ is a constant (in $\mathrm{MPa}^{0.10}$ ) between 0.40 and 0.60 depending on the texture, and $f_{s}$ and $f_{m}$ are the compressive strength of stone and mortar, respectively. Taking $K$ as an average value of 0.50 and using the values in Table 1 for $f_{s}$ and $f_{m}$, (1) gives $15.65 \mathrm{MPa}$ for $f_{c}$. As for the elastic modulus $E$ and tensile strength $f_{t}$ of the masonry, it is stated in the same reference that, where there is no opportunity to determine them via tests, their values can be taken in the $200 f_{c} \leq E \leq 2000 f_{c}$ and $0.03 f_{c} \leq f_{t} \leq 0.09 f_{c}$ ranges. It is implied that in the range related to the modulus of elasticity, $E>1000 f_{c}$ values may sometimes be far from reality, therefore large values for $E$ should be used with caution. Based on these, it was adopted to take $E=750 f_{c} \cong 11738 \mathrm{MPa}$ and $f_{t}=0.06 f_{c} \cong 1 \mathrm{MPa}$ in the study. The Poisson's ratio was taken as 0.20 , which is widely used for brittle materials. 
Regarding the unit weight, $\gamma$, of the masonry, it is obvious that this depends on the unit weights and volume fractions of its materials. It is impossible to know exactly the volume fractions, only an estimate can be made in this regard. In a historical masonry structure such as under consideration, $75 \%, 20 \%$ and 5\% volume fractions are reasonable values for stone, mortar (including filling material) and voids, respectively. Then the unit volume weight of masonry can be calculated by using of the following expression:

$\gamma=\varphi_{s} \gamma_{s}+\varphi_{m} \gamma_{m}+\varphi_{v} \gamma_{v}$

Here $\varphi_{s}, \varphi_{m}, \varphi_{v}$ and $\gamma_{s}, \gamma_{m}, \gamma_{v}$ show the volume fractions and the unit weights of stone, mortar and voids, respectively. Using unit weight values in Table 1 , taking $\gamma_{v}=0$, and adopting above estimated volume fractions, $\gamma$ is calculated as $23.37 \mathrm{kN} / \mathrm{m}^{3}$.

Thus, values of all necessary material properties of the structure have been determined. These are presented in Table 2 all together. The stress-strain, $\sigma-\varepsilon$, graphic formed artificially for use in the calculations is shown in Fig. 7. The behavior of plain concrete, which is brittle like masonry material, has been taken as basis. For compression, Hognestad's (1951) modified model, and for tension, Massicotte et al.'s (1990) model have been used.

Table 2 Material properties of Şarapsa Han used in calculations

\begin{tabular}{ccccc}
\hline $\begin{array}{c}\text { Unit weight, } \gamma \\
\left(\mathrm{kN} / \mathrm{m}^{3}\right)\end{array}$ & $\begin{array}{c}\text { Modulus of } \\
\text { elasticity, } E \\
(\mathrm{MPa})\end{array}$ & $\begin{array}{c}\text { Compressive } \\
\text { strength, } f_{c}(\mathrm{MPa})\end{array}$ & $\begin{array}{c}\text { Tensile } \\
\text { strength, } f_{t}(\mathrm{MPa})\end{array}$ & $\begin{array}{c}\text { Poisson's } \\
\text { ratio, } v\end{array}$ \\
\hline 23.37 & 11738 & 15.65 & 1 & 0.20 \\
\hline
\end{tabular}

In this study, for the calculations Abaqus finite element program was employed. The nonlinear material behavior explained above was introduced to the program, and the option to consider the effect of nonlinear geometry changes was activated. In Abaqus, the concrete damaged plasticity (CDP) model provides an opportunity for modeling of concrete and other quasi-brittle materials such as masonry. Details of the model can be found in user manual of Abaqus. The model 
uses a damage parameter, $d$, to take into account degradation in modulus of elasticity of the material due to damage. In various studies on masonry structures, it is seen that the value 0.95 is often used as an upper limit for this parameter. In the present study, the value 0.87 was used for this parameter.

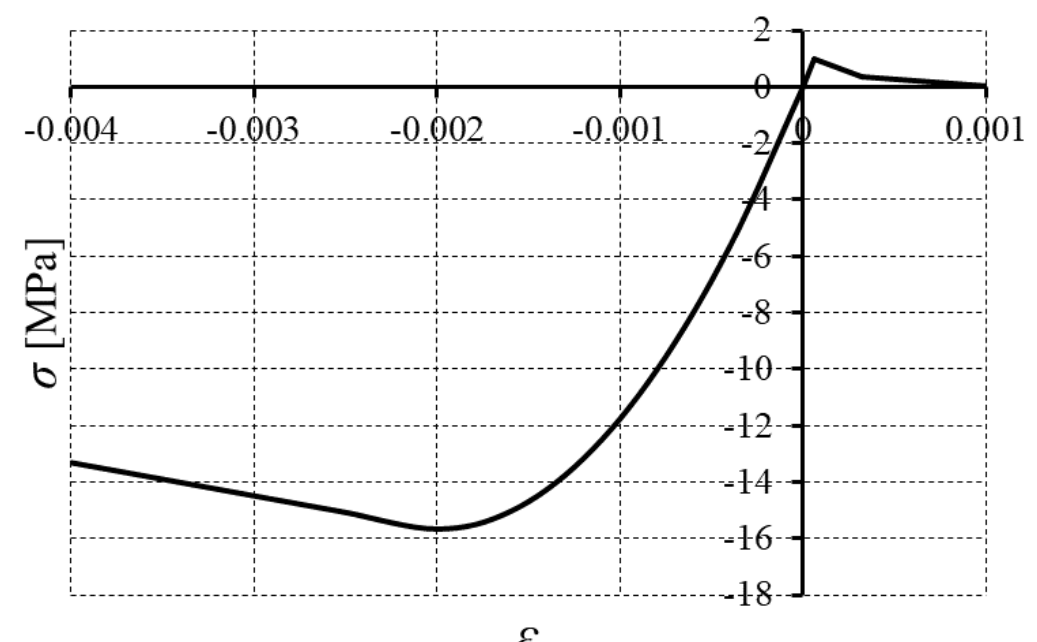

Fig. 7 The artificially formed uniaxial $\sigma-\varepsilon$ graphic of the homogenized masonry material of the Han

When using the CDP model, other required parameters are; the dilation angle $\psi$, the ratio of initial equibiaxial to initial uniaxial compressive strength $f_{b 0} / f_{c 0}$, the eccentricity $\epsilon$, the $K_{c}$ parameter, and the viscosity parameter $\mu$. For the analyses, the adopted values of the parameters are given in Table 3. These values are either the default values in the user manual of Abaqus or the values that are compatible with those in the relevant literature (see for example to Valente and Milani, 2016).

Table 3 Damaged plasticity parameters used in the analyses

\begin{tabular}{ccccc}
\hline Dilation angle, $\psi$ & $f_{b 0} / f_{c 0}$ & Eccentricity, $\epsilon$ & $K_{c}$ & Viscosity parameter, $\mu$ \\
\hline $10^{\circ}$ & 1.16 & 0.1 & 0.667 & 0.0001 \\
\hline
\end{tabular}

\subsection{Buttress forms considered for the structure}

As already stated, main purpose of the present study is to investigate the effect of buttress form on transverse seismic resistance of high masonry walls. In this context, a compilation has been made 
from the buttress forms encountered in historical masonry structures reviewed in Section 2. The selected forms are shown in Fig. 8 as lined up on a wall. As can be seen from the figure, there are, among these forms, the most common types (Fig. 8a, b, c, h), the stepped types (Fig. $8 \mathrm{~d}_{1}, \mathrm{~d}_{2}$ ), the combined types (Fig. 8e $1, e_{2}, e_{3}$ ), the less common types (Fig. $8 f_{1}, f_{2}$ ), and the rare types (Fig. $8 g_{1}, g_{2}$, $\mathrm{g}_{3}$ ). In total, fourteen buttress forms have been considered. It can be said that the variety of forms is rich enough.

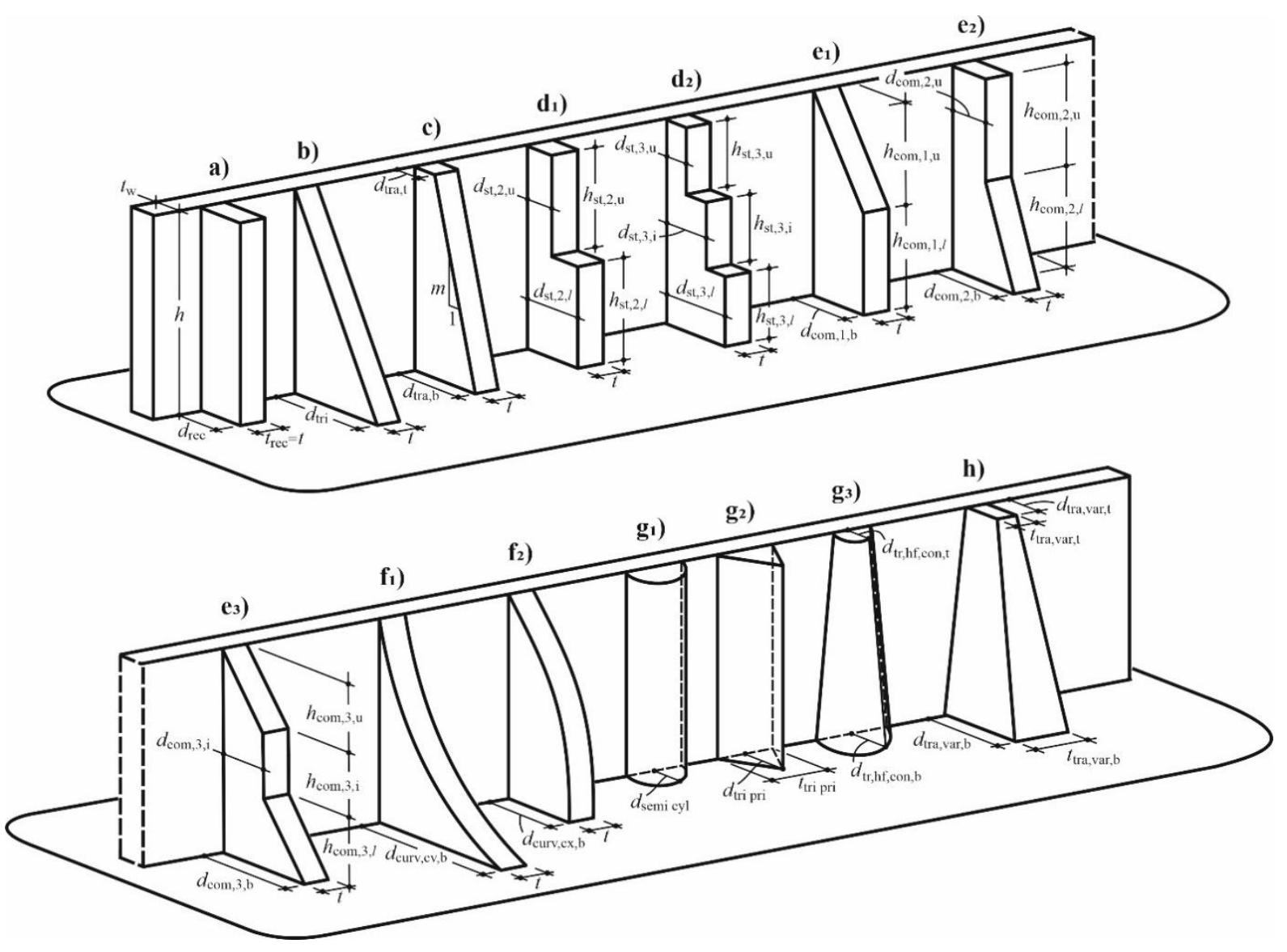

Fig. 8 Buttress forms considered in the analyses: a) rectangular b., b) triangular b., c) trapezoidal b., $d_{1}$ ) two-stepped $b ., d_{2}$ ) three-stepped $b ., e_{1}$ ) first type combined b., $e_{2}$ ) second type combined $b ., e_{3}$ ) third type combined $b ., f_{1}$ ) concave curvilinear $b ., f_{2}$ ) convex curvilinear $b ., g_{1}$ ) semi-

cylindrical b., $\mathrm{g}_{2}$ ) triangular prism $\mathrm{b} ., \mathrm{g}_{3}$ ) truncated half-conic $\mathrm{b}$., and $\mathrm{h}$ ) trapezoidal buttress with varying thickness

There are some notations in Fig. 8 about the geometric features of the considered buttresses. These are given in Table 4. It should be noted that, the dimensions perpendicular and parallel to the wall, of a buttress are named as "depth" and "thickness", respectively. 
Table 4 Notations about the geometric features of the considered buttresses, Fig. 8

\begin{tabular}{|c|c|}
\hline Notation & Meaning \\
\hline$h$ & The height of the wall and of the buttresses \\
\hline$t_{\mathrm{w}}$ & Thickness of the wall \\
\hline$d_{\text {rec }}$ & Depth of the rectangular buttress \\
\hline$d_{\text {tri }}$ & Depth (base depth) of the triangular buttress \\
\hline$d_{\text {tra,b }}$ & Base depth of the trapezoidal buttress \\
\hline$d_{\text {tra,t }}$ & Top depth of the trapezoidal buttress \\
\hline$d_{\mathrm{st}, 2, \mathrm{u}}$ & Depth of the upper part of the two-stepped buttress \\
\hline$d_{\mathrm{st}, 2, l}$ & Depth of the lower part of the two-stepped buttress \\
\hline$d_{\mathrm{st}, 3, \mathrm{u}}$ & Depth of the upper part of three-stepped buttress \\
\hline$d_{\mathrm{st}, 3, \mathrm{i}}$ & Depth of the intermediate part of the three-stepped buttress \\
\hline$d_{\mathrm{st}, 3, l}$ & Depth of the lower part of the three-stepped buttress \\
\hline$d_{\mathrm{com}, 1, \mathrm{~b}}$ & Base depth of the first type combined buttress \\
\hline$d_{\mathrm{com}, 2, \mathrm{~b}}$ & Base depth of the second type combined buttress \\
\hline$d_{\mathrm{com}, 2, \mathrm{u}}$ & Depth of the upper part of the second type combined buttress \\
\hline$d_{\mathrm{com}, 3, \mathrm{~b}}$ & Base depth of the third type combined buttress \\
\hline$d_{\mathrm{com}, 3, \mathrm{i}}$ & Depth of the intermediate part of the third type combined buttress \\
\hline$d_{\text {cur,cv, b }}$ & Base depth of the curvilinear concave buttress \\
\hline$d_{\text {cur,cx,b }}$ & Base depth of the curvilinear convex buttress \\
\hline$d_{\text {semi cyl }}$ & Depth (radius) of the semi-cylindrical buttress \\
\hline$d_{\text {tri pri }}$ & Depth of the triangular prism buttress \\
\hline$d_{\mathrm{tr}, \mathrm{hf}, \mathrm{con}, \mathrm{b}}$ & Base depth (radius) of the truncated half-conic buttress \\
\hline$d_{\mathrm{tr}, \mathrm{hf}, \mathrm{con}, \mathrm{t}}$ & Top depth (radius) of the truncated half-conic buttress \\
\hline$d_{\text {tra, var,b }}$ & Base depth of the trapezoidal buttress with varying thickness \\
\hline$d_{\text {tra,var,t }}$ & Top depth of the trapezoidal buttress with varying thickness \\
\hline$h_{\mathrm{st}, 2, \mathrm{u}}$ & Height of the upper part of the two-stepped buttress \\
\hline$h_{\mathrm{st}, 2, l}$ & Height of the lower part of the two-stepped buttress \\
\hline$h_{\mathrm{st}, 3, \mathrm{u}}$ & Height of the upper part of the three-stepped buttress \\
\hline$h_{\mathrm{st}, 3, \mathrm{i}}$ & Height of the intermediate part of the three-stepped buttress \\
\hline$h_{\mathrm{st}, 3, l}$ & Height of the lower part of the three-stepped buttress \\
\hline$h_{\mathrm{com}, 1, \mathrm{u}}$ & Height of the upper part of the first type combined buttress \\
\hline$h_{\mathrm{com}, 1, l}$ & Height of the lower part of the first type combined buttress \\
\hline$h_{\mathrm{com}, 2, \mathrm{u}}$ & Height of the upper part of the second type combined buttress \\
\hline$h_{\mathrm{com}, 2, l}$ & Height of the lower part of the second type combined buttress \\
\hline$h_{\mathrm{com}, 3, \mathrm{u}}$ & Height of the upper part of the third type combined buttress \\
\hline$h_{\mathrm{com}, 3, \mathrm{i}}$ & Height of the intermediate part of the third type combined buttress \\
\hline$h_{\mathrm{com}, 3, l}$ & Height of the lower part of the third type combined buttress \\
\hline$t_{\mathrm{rec}}=t$ & Thickness of the rectangular, triangular,..., and curvilinear buttresses \\
\hline$t_{\text {tri pri }}$ & Thickness of the triangular prism buttress \\
\hline$t_{\text {tra, var,b }}$ & Base thickness of the trapezoidal buttress with varying thickness \\
\hline$t_{\text {tra,var,t }}$ & Top thickness of the trapezoidal buttress with varying thickness \\
\hline$m$ & Slope of the trapezoidal buttress \\
\hline
\end{tabular}

\subsection{The analysis method: Nonlinear static analysis (Pushover analysis)}

\subsubsection{A summary of the method}

It can be said that, it is not an easy task to determine the seismic resistance of historic masonry structures. Because as is known, there are many factors that cause this. The fact that brittle failure 
occurs in masonry material under seismic loads, due to its nature, and that the earthquake is a highly complex event are only two of them.

In this study, nonlinear static analysis method, also known as pushover analysis method, was preferred as the analysis method. Its suitability for the purpose of the study and its simplicity are the main factors in its preference. It will be appreciated that if a complex method such as the time history analysis method is used, the effects of the buttress form on the seismic resistance of the walls may not be distinguished as easily as in a simple nonlinear static analysis.

As it is known, the nonlinear static analysis method is a quasi-static method. With the method, it is possible to make a general seismic assessment with less computational labor, time and cost by completely neglecting the dynamic effects of the earthquake or approximating them in a quasi-static manner. Although more approximate, the method is powerful and practical, and is among the primary tools used for evaluating masonry structures, (DeJong (2009), Endo et al. (2016)).

In nonlinear static analysis method, dynamic earthquake loading is typically simplified as a quasi-static loading in one of the following two ways:

* The first way is to apply a progressively increasing unilateral acceleration to the modelled structure up to the exceedance of the maximum lateral resisting capacity and the development of a failure mechanism. This way is equivalent to subject the structure to a progressively increasing unidirectional horizontal ground motion. This option conservatively ignores the fact that actual ground motions only occur for a short period of time, and also neglects the possibility of resonant amplification, (DeJong (2009), Illampas et al. (2020)).

* The second way involves applying monotonously increased horizontal forces, adhering to a predefined distribution pattern along the height of the structure to approximate the effects of an earthquake. In this procedure, the relative magnitudes of the forces are distributed with preference towards the top of the structure, accounting for amplification caused by dynamic resonance effects (DeJong, 2009).

Either way, at the end of the analysis, the relationship between base shear force and control node displacement is plotted. In this study, the first way has been used. 


\subsubsection{Calculation procedure}

The aim is to determine the effect of buttress form on the transverse seismic resistance of high masonry walls. This will be achieved by performing nonlinear static analysis both in the calculation model of the structure, Fig. $6 \mathrm{~b}$, and in each new model obtained by changing only the buttress form, Fig. 8, of this model. By comparing the capacity curves or seismic coefficients obtained from these analyses, "the effect of form on resistance" will be understood. Here, while presenting the calculation procedure, Illampas et al. (2020) has been taken as example by virtue of the fact that the similarity of the structure type and the same calculation method used.

To perform nonlinear static analysis on a model, a uniformly applied, unidirectional, mass proportional loading pattern has been considered. Loading has been progressively increased up to the exceedance of the maximum lateral resisting capacity and the development of a failure mechanism. As mentioned above, such a loading is equivalent to subject the model to a gradually increasing unidirectional horizontal ground motion. It is illustrated schematically in Fig. 9 on the model having triangular buttresses. Loading has been imposed by specifying a uniform gravitational field in the horizontal direction. This resulted in generation of nodal forces proportional to the point-wise spatial distribution of mass. Endo et al. (2016) observed that nonlinear static analyses performed using mass proportional loading functions can produce load capacity values sufficiently close to the results obtained by nonlinear dynamic analyses.

The nonlinear static analysis has been carried out in two consecutive numerical steps. In the first step, their own weights have been applied to the models, and in the second step, monotonically increasing lateral forces have been incrementally enforced on them at rather small time intervals over a fictitious period of 1 second. It should be stated that there is no physical meaning of "time" in the analysis and that the computed responses are not time-dependent. Here, "time" is a scalar parameter used by the Abaqus for determining load variation during the solution process. In the analysis, the effect of nonlinearity, both material and geometric, was taken into account. 


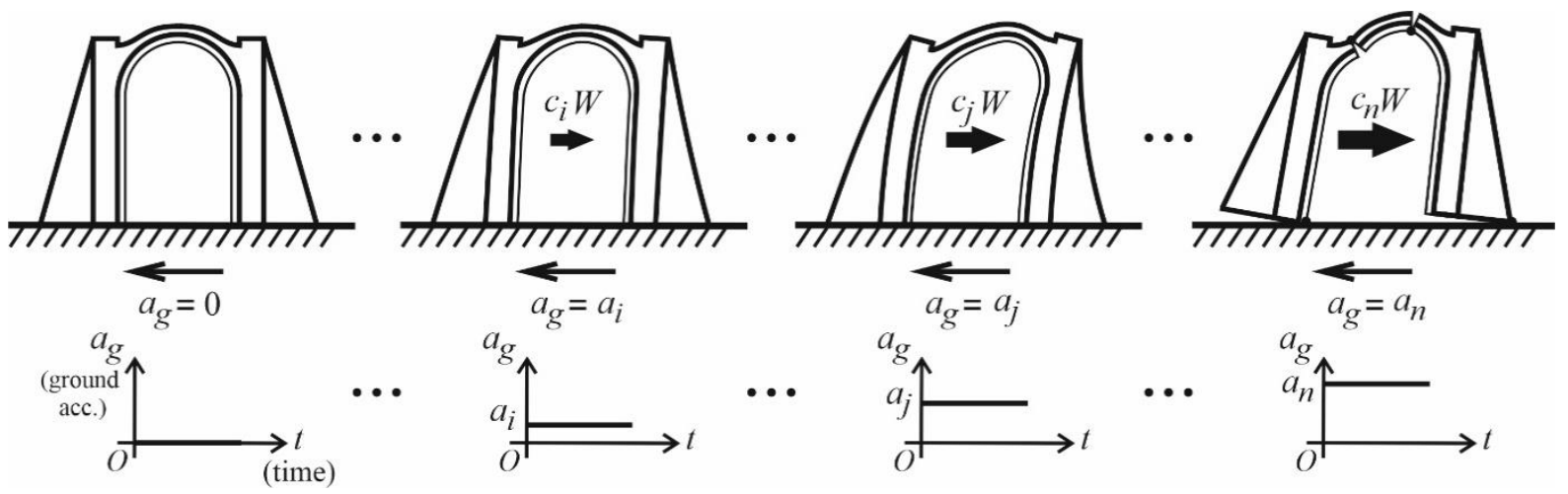

Fig. 9 A schematic representation of the increasing lateral forces and failure mechanism occuring in triangular buttressed model due to the gradually increasing unidirectional horizontal earthquake ground motion

For each model, result of the above summarized analysis has been presented as a capacity curve, i.e. the curve of base shear force vs lateral displacement of a preselected control node. Base shear force has been determined as the sum of the horizontal reaction forces computed at the nodes on the base section of the model, and the middle node on the ridge of the vault has been chosen as the control node. And, maximum seismic coefficient $c_{n}$, Fig. 9, which represents the largest transverse seismic force to which the model can resist, has been obtained as:

$c_{n}=$ Maximum base shear force/Self-weight of the model $=R_{\max } / W_{\text {model }}$

Thus, the analysis for the model is completed. By comparing the maximum capacities or seismic coefficients obtained for the models, the effect of the buttress form on the transverse seismic resistance of the walls is determined.

\subsection{Performed analyses}

To create the models, firstly a "basic model" consisting of two opposite walls, vault and interior arch was formed. Then, by adding each buttress form in Fig. 8 in the middles of the outer surfaces of the walls of this model, the models having different buttress forms were obtained. When forming the 
finite element mesh of the models (basic and other), C3D8R (8-node linear brick, reduced integration, hourglass control) solid element was used. Different mesh sizes were tested, starting with the coarse ones, until further improvement in the results were achieved by refining the meshes and stable results were reached. In addition, in nonlinear static analysis kinetic energy was controlled and it was checked whether the inertia effects remained at negligible levels. To save time, calculations were performed on halves of the models. Moreover, the bottom cross-sections of the models were fixed, i.e., all the degrees freedom of all nodes in these sections were restricted.

Here, besides the beginning analyses that examine the effect of buttress depth on seismic capacity, two groups of analyses are performed in which the effect of the buttress form on the capacity is investigated.

\subsubsection{Beginning analyses: Investigation of the influence of buttress depth}

As the depth of a buttress increases, the moment of inertia about bending axis of its cross-sections and thus the stiffness contribution to the wall it supports will also increase. It is obvious, then, that the "buttress depth" is one of the basic parameters for the seismic resistance of a building-type masonry structure. Here, the influence of this parameter on transverse seismic capacity will be examined. The investigation will only be carried out on the rectangular buttressed model.

In this context, firstly the "calculation model" shown in Fig. 6b, whose buttress depth is 2.20 $\mathrm{m}$, has been analysed and base shear force versus control node displacement graphic, that is the capacity curve has been obtained. Then, the non-buttressed version of this model, i.e. the "basic model" has been analysed. In addition, calculation model's modified versions which have buttress depths of $1.10 \mathrm{~m}, 3.30 \mathrm{~m}$ and $4.40 \mathrm{~m}$ have been calculated. These depth values are respectively half, one and a half times and two times of the buttress depth value in the calculation model. The results of the calculations are presented in Fig. 10a. The increase in transverse seismic capacity with the increase in buttress depth is rather clear. Therefore, as expected, the buttress depth has a great influence on the seismic capacity of a building-type masonry structure. Figure 10b presents the 
variation of maximum seismic capacity depending on the buttress depth. It is seen that there is nearly a linear relationship between capacity and buttress depth.
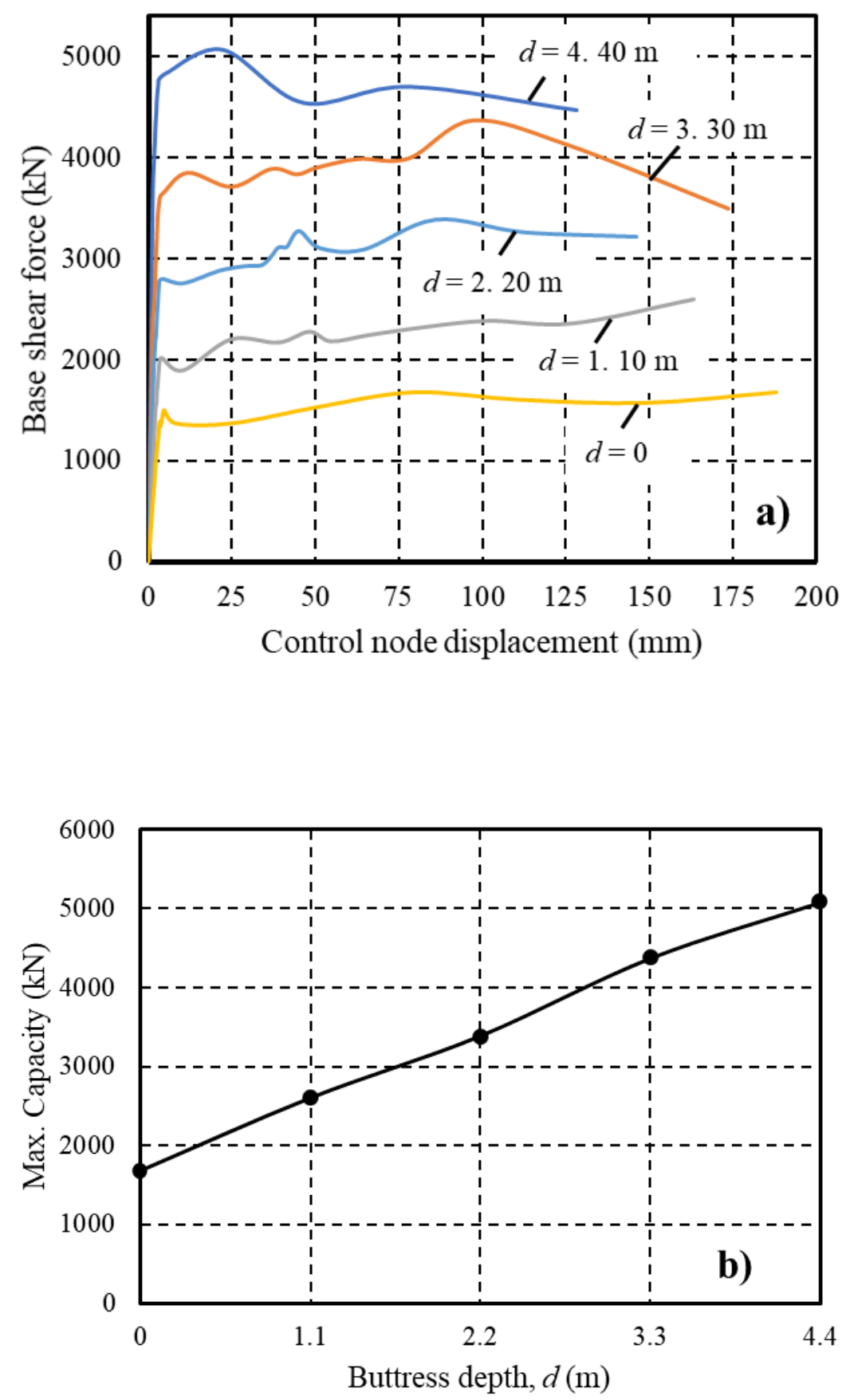

Fig. 10 Effect of buttress depth: a) Capacity curves of the rectangular buttressed model for different buttress depths, b) Variation of the maximum capacity of the model with the buttress depth 


\subsubsection{First group analyses}

In the analyses in this group, the volumes of the buttresses shown in Fig. 8 are taken as equal to each other. It is clear that this condition is set for the purpose of using an equal amount of material in all buttresses. Because only in this way it will be meaningful to compare the seismic resistances to be determined by the analyses. The first buttress is the rectangular buttress, which is also seen in the calculation model of the structure, Fig. 6b. Its volume, that is equal to $V_{\mathrm{rec}}=h \times d_{\mathrm{rec}} \times t=11.10 \times 2.20$ $\times 1.35 \cong 32.97 \mathrm{~m}^{3}$, was taken as constant volume value for all other buttresses. The dimensions of the buttresses are given in Table 5. The thickness values of the buttresses from $b$ to $f_{2}$ in Fig. 8 were taken as equal to the thickness of the rectangular buttress. It is clear that there are theoretically unlimited options for trapezoidal buttress depending on its base and top depths, Fig. 8c. By assigning one of the depths, the other can be determined according to the constant volume criterion. Three options have been shown in the table. The situation is similar for stepped buttresses, Fig. $8 \mathrm{~d}_{1}$ and $\mathrm{d}_{2}$. For example in two-stepped buttress, when the height and depth of the lower part are assigned, the depth of the upper part can be determined easily using the volume criterion. In two-stepped buttress, we have adjusted the heights of the steps to be equal and the depth of the lower step to be twice that of the upper step. In three-stepped buttress, an arrangement have been made in which the heights of the steps to be equal and the depths of the intermediate and upper steps to be two-thirds and one-thirds that of the lower step. The three types of combined buttresses considered, Fig. $8 \mathrm{e}_{1}, \mathrm{e}_{2}$ and $\mathrm{e}_{3}$, were sized by following the similar considerations. Curvilinear buttresses, Fig. $8 \mathrm{f}_{1}$ and $\mathrm{f}_{2}$, have second degree parabola function. For the concave parabola curve, the vertical line on the wall face is tangent, and for the convex one, the tangent at the bottom point of the curve is vertical. Base depths, $d_{\mathrm{cur}, \mathrm{cv}, \mathrm{b}}, d_{\mathrm{cur}, \mathrm{cx}, \mathrm{b}}$, of these buttresses have been calculated as $6.60 \mathrm{~m}$ and $3.30 \mathrm{~m}$ respectively. A simple mathematical calculation, using the volume criterion, gave the depth, i.e. radius, of the semi-cylindrical buttress, Fig. $8 \mathrm{~g}_{1}$, as $1.375 \mathrm{~m}$. Cross-section of triangular prism buttress, Fig. $8 \mathrm{~g}_{2}$, has been selected as equilateral triangle. In this case, thickness of it at its interface with the wall, $t_{\text {tri pri, }}$ and its depth, $d_{\text {tri pri }}$, have been obtained as $2.62 \mathrm{~m}$ and $2.27 \mathrm{~m}$, respectively. The truncated half-conical buttress has been formed so that the bottom depth to be twice the top depth. For the variable thickness trapezoidal 
buttress, which is the last buttress we consider, a similar design, i.e. a design in which the depth and thickness values of the base are twice the top cross section's values has been made.

Table 5 Dimensions of the buttresses in the first group analyses

\begin{tabular}{|c|c|}
\hline Buttress form & Dimensions (in meter) \\
\hline Rectangular (Fig. 17a) & $h=11.10, t_{\mathrm{rec}}=1.35, d_{\mathrm{rec}}=2.20$ \\
\hline Triangular (Fig. 17b) & $h=11.10, t=1.35, d_{\mathrm{tri}}=4.40$ \\
\hline Trapezoidal (Fig 17c) & $\begin{array}{l}\text { Type } 1: h=11.10, t=1.35, d_{\text {tra, }}=3.30, d_{\text {tra, }}=1.10 \rightarrow m \cong 5.05 \% \\
\text { Type 2: } h=11.10, t=1.35, d_{\text {tra, }}=3.85, d_{\text {tra, }}=0.55 \rightarrow m \cong 3.36 \% \\
\text { Type 3: } h=11.10, t=1.35, d_{\text {tra, }}=2.75, d_{\text {tra, }}=1.65 \rightarrow m \cong 10.09 \%\end{array}$ \\
\hline $\begin{array}{l}\text { Two-stepped } \\
\left.\text { (Fig. } 17 d_{1}\right)\end{array}$ & $\begin{array}{l}h=11.10, t=1.35, d_{\mathrm{st}, 2, \mathrm{u}}=1.47, d_{\mathrm{st}, 2, l}=2.93 \\
h_{\mathrm{st}, 2, \mathrm{u}}=5.55, h_{\mathrm{st}, 2, l}=5.55\end{array}$ \\
\hline $\begin{array}{l}\text { Three-stepped } \\
\text { (Fig. } 17 \mathrm{~d}_{2} \text { ) }\end{array}$ & $\begin{array}{l}h=11.10, t=1.35, d_{\mathrm{st}, 3 \mathrm{u}}=1.10, d_{\mathrm{st}, 3 \mathrm{i}}=2.20, d_{\mathrm{st}, 3, l}=3.30 \\
h_{\mathrm{st}, 3, \mathrm{u}}=3.70, h_{\mathrm{st}, 3, \mathrm{i}}=3.70, h_{\mathrm{st}, 3, l}=3.70\end{array}$ \\
\hline $\begin{array}{l}\text { First type combined } \\
\text { (Fig. 17e } \mathrm{e}_{1} \text { ) }\end{array}$ & $\begin{array}{l}h=11.10, t=1.35, d_{\mathrm{com}, 1, \mathrm{~b}}=2.93 \\
h_{\mathrm{com}, 1, \mathrm{u}}=5.55, h_{\mathrm{com}, 1, l}=5.55\end{array}$ \\
\hline $\begin{array}{l}\text { Second type combined } \\
\text { (Fig. 17 } \mathrm{e}_{2} \text { ) }\end{array}$ & $\begin{array}{l}h=11.10, t=1.35, d_{\mathrm{com}, 2, \mathrm{~b}}=3.52, d_{\mathrm{com}, 2, \mathrm{u}}=1.76 \\
h_{\mathrm{com}, 2, \mathrm{u}}=5.55, h_{\mathrm{com}, 2, l}=5.55\end{array}$ \\
\hline $\begin{array}{l}\text { Third type combined } \\
\text { (Fig. 17 } \mathrm{e}_{3} \text { ) }\end{array}$ & $\begin{array}{l}h=11.10, t=1.35, d_{\mathrm{com}, 3, \mathrm{~b}}=4.40, d_{\mathrm{com}, 3, \mathrm{i}}=2.20 \\
h_{\mathrm{com}, 3, \mathrm{u}}=3.70, h_{\mathrm{com}, 3, \mathrm{i}}=3.70, h_{\mathrm{com}, 3, l}=3.70\end{array}$ \\
\hline $\begin{array}{l}\text { Curvilinear concave } \\
\text { (Fig. } 17 \mathrm{f}_{1} \text { ) }\end{array}$ & $h=11.10, t=1.35, d_{\mathrm{cur}, \mathrm{cv}, \mathrm{b}}=6.60$ \\
\hline $\begin{array}{l}\text { Curvilinear convex (Fig. } \\
17 \mathrm{f}_{2} \text { ) }\end{array}$ & $h=11.10, t=1.35, d_{\mathrm{cur}, \mathrm{cx}, \mathrm{b}}=3.30$ \\
\hline Semi-cyl. (Fig. 17g g $_{1}$ & $h=11.10, d_{\text {semi cyl }}=1.375$ \\
\hline Triang. pri. (Fig. $17 g_{2}$ ) & $h=11.10, t_{\text {tri pri }}=2.62, d_{\text {tri pri }}=2.27$ \\
\hline $\begin{array}{l}\text { Truncated half-conic } \\
\text { (Fig. } 17 \mathrm{~g}_{3} \text { ) }\end{array}$ & $h=11.10, d_{\mathrm{tr}, \mathrm{hf}, \mathrm{con}, \mathrm{b}}=1.80, d_{\mathrm{tr}, \mathrm{hf}, \mathrm{con}, \mathrm{t}}=0.90$ \\
\hline $\begin{array}{l}\text { Trapez. with varying } \\
\text { thickness (Fig. 17h) }\end{array}$ & $\begin{array}{l}h=11.10, d_{\text {tra, var, }}=3.77, d_{\text {tra, var }, \mathrm{t}}=1.89 \\
t_{\text {tra,var, } \mathrm{b}}=1.35, t_{\text {tra, var } \mathrm{t}}=0.68\end{array}$ \\
\hline
\end{tabular}

Now let's move on to the presentation and discussion of results obtained from the analyses made in this group. While doing this, firstly the results belonging to the models with different buttresses will be compared in subgroups, and then a collective comparison of all results will be made. Since rectangular buttress is the most common buttress type in historical architecture, the result of the rectangular buttressed model will be present in all of the comparisons. 
As expressed in the Section 2, the most common buttresses in historical masonry structures are rectangular, triangular and trapezoidal buttresses. The capacity curves of the models having these buttresses are presented in Fig. 11. It can be seen from the figure that the transverse seismic resistance of the triangular buttressed model first and then the trapezoidal buttressed one is saliently greater than that of the rectangular buttressed model.

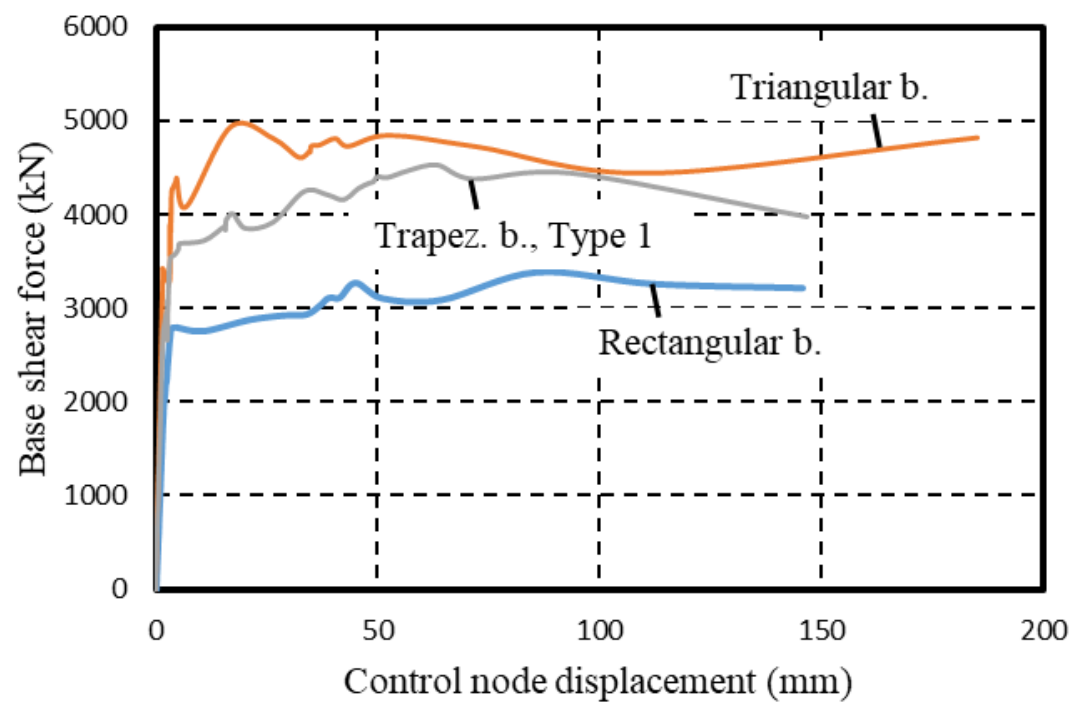

Fig. 11 Capacity curves of rectangular, triangular and trapezoidal (Type 1) buttressed models

Capacity curves belonging to the Type 1, Type 2 and Type 3 trapezoidal buttressed models, which their buttresses have 5.05\%, 3.36\% and 10.09\% slopes, respectively, Table 5, are given in Fig. 12a. It can be seen that the seismic resistance increases considerably as the buttress slope decreases. In other words, the more oblique the buttress, the greater the seismic resistance. The triangular and rectangular buttresses are limit states of the trapezoidal buttress. Comparison of the seismic capacities of the models having these buttresses is presented in Fig. 12b. As can be seen, the seismic resistance of the model having trapezoidal buttresses with less slope (Type 2) is close to that of the triangular buttressed model, and the resistance of the model having trapezoidal buttresses with higher slope (Type 3) is close to that of the rectangular buttressed model. 

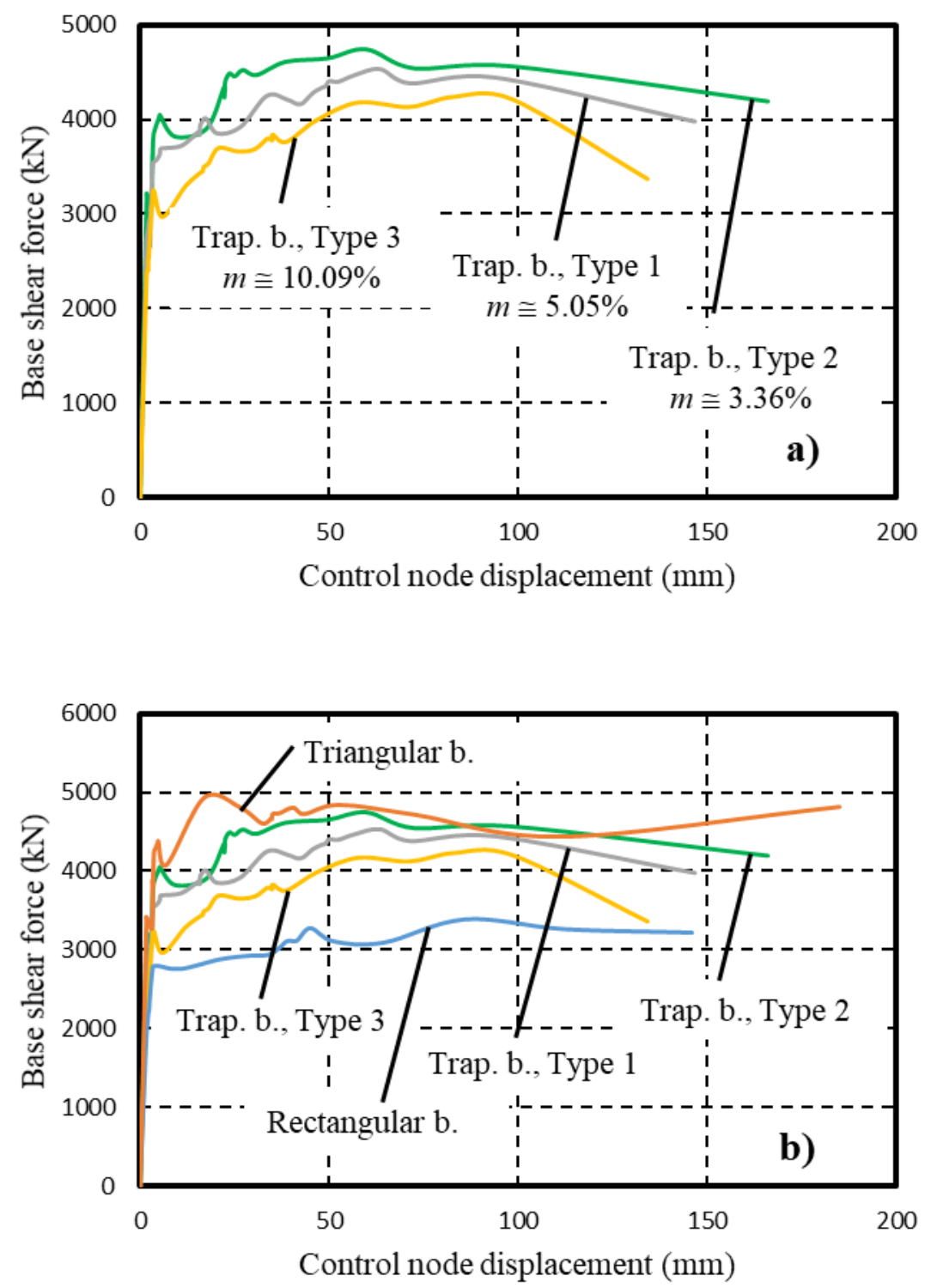

Fig. 12 a) Capacity curves of Type1, Type 2 and Type 3 trapezoidal buttressed models (Effect of slope of the trapezoidal buttress on seismic resistance), b) Comparison of the seismic capacities of trapezoidal buttressed models with those of the rectangular and triangular buttressed models

Stepped rectangular buttresses are a very common buttress type especially in European historical architecture. Here, only two- and three-stepped versions of this buttress have been considered, Figs. 8d1, d2. Capacity curves of the models having these buttresses are plotted in Fig. 13a. It is evident that, provided that heights and depths of its parts are arranged harmoniously, a stepped buttress will approach a triangular buttress, when the number of its steps increases. And, if 
there is no steps, then it becomes a rectangular buttress. This situation can be clearly seen in Fig. 13b where the capacity curves of the models with stepped buttresses and the models with triangular and rectangular buttresses have been shown together.
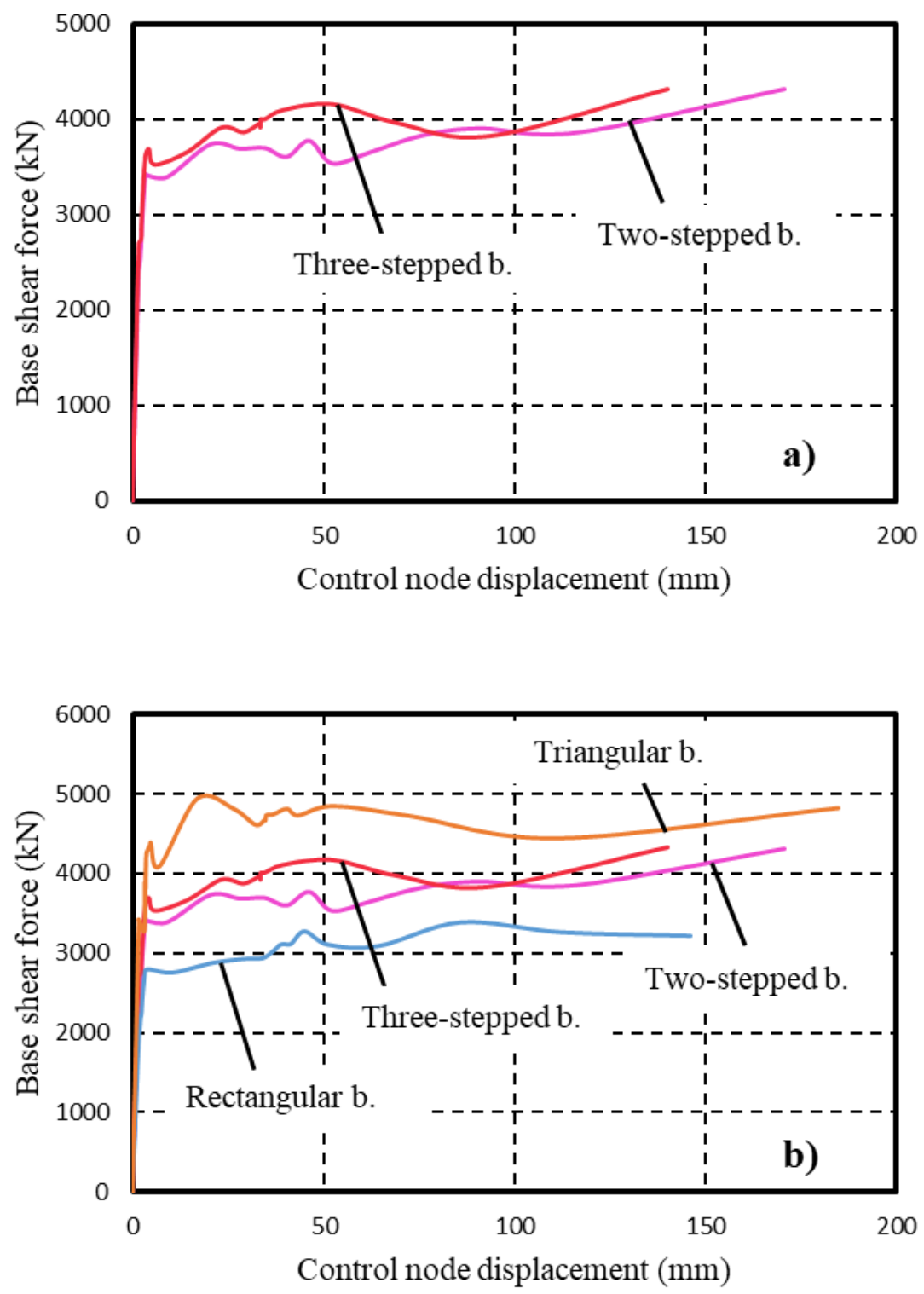

Fig. 13 a) Capacity curves of two- and three-stepped buttressed models, b) Comparison of the seismic capacities of stepped buttressed models with those of the rectangular and triangular buttressed models

If it is said that "there are countless types of combined buttresses in historical masonry architecture", this would not be an exaggerated expression. The capacity curves of models having combined buttresses considered in the present study, Fig. 8e1, e2 and e3, were obtained as in Fig. 14. 
Of course, if other types of combined buttresses were considered, different curves would be encountered. It can be clearly seen from Fig. 14 that the arrangement of the combined buttress significantly affects the seismic capacity.

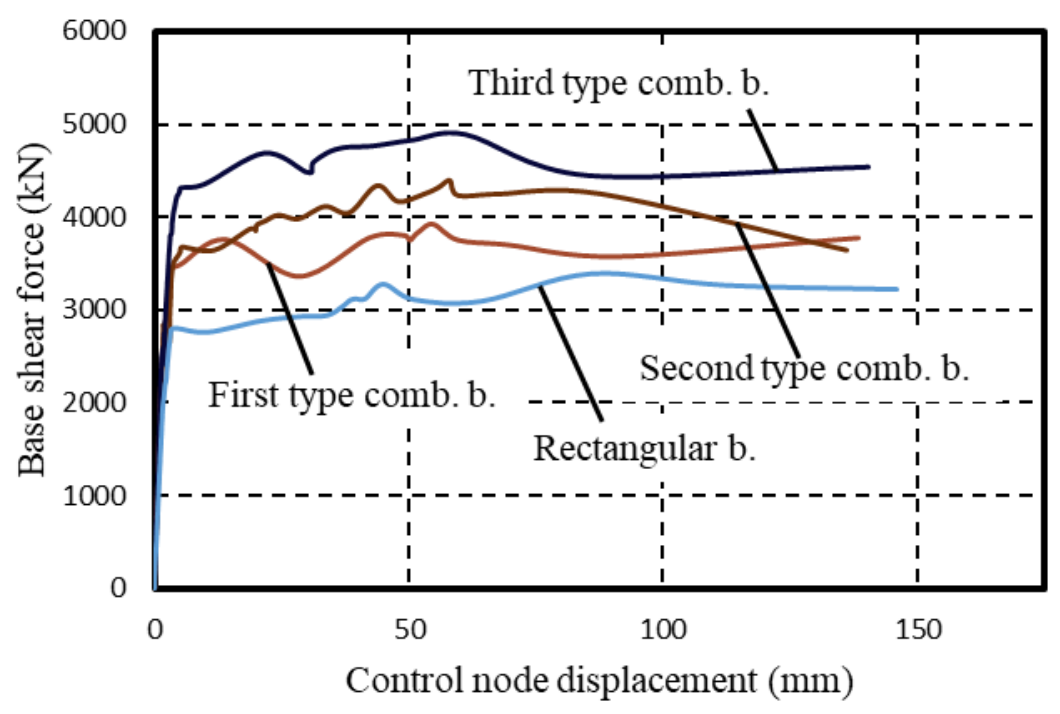

Fig. 14 Capacity curves of considered combined buttressed models, and comparison with the capacity curve of the rectangular buttressed model

As curvilinear buttresses, two, parabola shaped buttress, one concave and the other convex, were considered, Fig. $8 \mathrm{f}_{1}$ and $\mathrm{f}_{2}$. The capacity curves of the models having these buttresses, and again for comparison, curve of the rectangular buttressed one, are given in Fig. 15. It is seen that both models have much higher seismic resistance than the rectangular buttressed model. Among the models with different buttress forms that we took into consideration, it was determined that the curvilinear concave buttressed model has the highest transverse seismic resistance. With a seismic resistance of $5520.29 \mathrm{kN}$, this model has a $63 \%$ higher resistance than the rectangular buttressed model which has a resistance of $3382.91 \mathrm{kN}$. When historical masonry architecture is reviewed, it is seen that these curvilinear concave buttresses had been mostly preferred in the upper parts of the structures. This situation can be seen, for example, in the Cuetzalan del Progreso Church in Mexico, the San Frediano Church in Italy and the Cadiz Cathedral in Spain. It is predicted that, besides their 
aesthetics, these curvilinear concave buttresses were used in the upper parts of these structures, as they do not obstruct the view thanks to the their form.

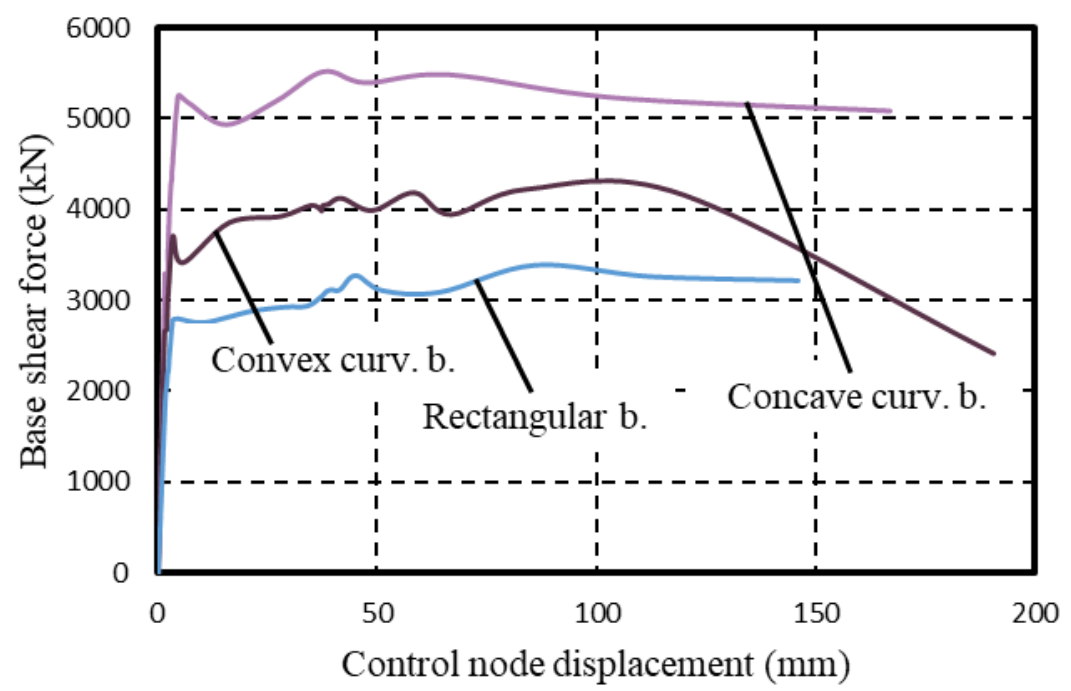

Fig. 15 Capacity curves of considered curvilinear buttressed models, and comparison with the capacity curve of the rectangular buttressed model

Capacity curves of the models propped with semi-cylindrical, triangular prism and truncated half-conic buttresses, together with the curve of rectangular buttressed model are presented in Fig. 16. It is seen that, except the curve belonging to the semi-cylindrical buttressed model, curves of other three models are close to each other. Only in the middle and final stages of its analysis the behavior of the triangular prism buttressed model differs some from that of the truncated half-conic buttressed model and the rectangular buttressed model. The capacity of the model supported by semi-cylindrical buttresses is noticeably below the capacities of models supported by other buttresses. Towards the last stages of their analysis, the behavior of the semi-cylindrical buttressed model and the triangular prism buttressed model have emerged close to each other.

As can be seen from Fig. 8, the last buttress form considered is trapezoidal buttress of variable thickness. With the curve of the model supported with this buttress, and for comparison, the curves of the models with normal trapezoidal buttresses (Table 5, Type 1) and rectangular buttresses are shown in Fig. 17. It is seen that, except for the last stages of their analysis, the behavior of the trapezoidal 
buttressed models is quite similar. The seismic capacity of both trapezoidal buttress supported models is considerably higher than that of the rectangular buttressed model. In the second section of the study it was stated that trapezoidal buttresses are one of the most widely used buttresses in historical masonry structures. It is understood from the results obtained that this situation cannot be casual. Because the ancient builders who understood the importance of the buttress must have comprehended absolutely that the buttress form would also be important.

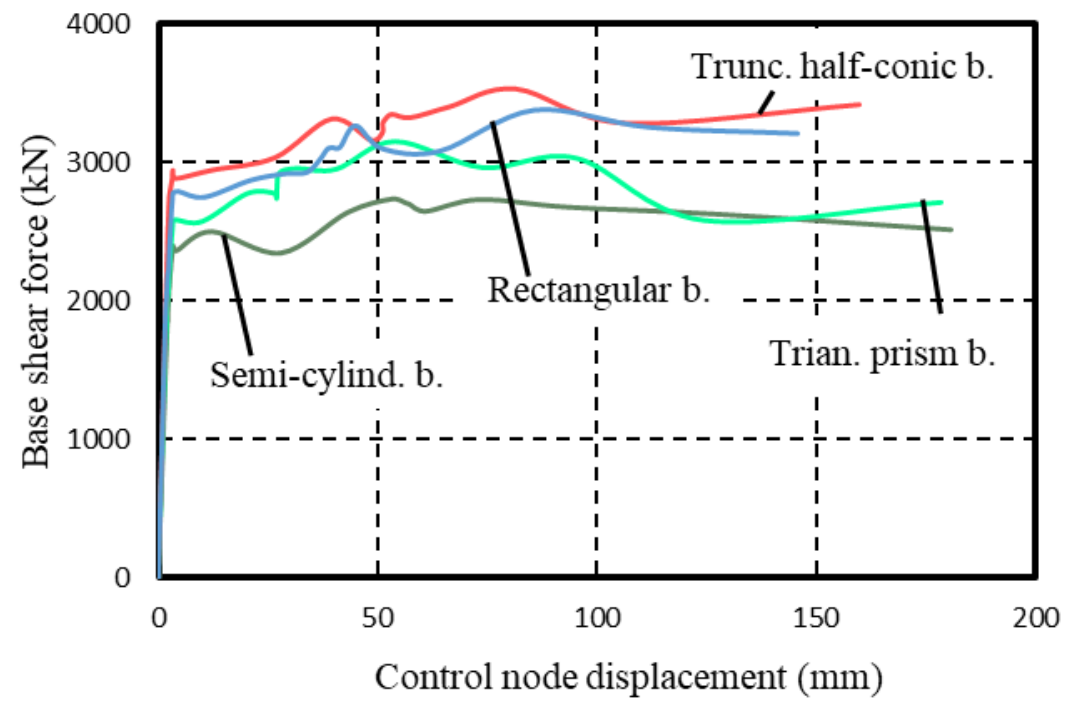

Fig. 16 Capacity curves of semi-cylindrical, triangular prism and truncated half-conic buttressed models, and comparison with the capacity curve of the rectangular buttressed model

A collective comparison of the results from these first group analyses is presented in Table 6 . The table lists the maximum base shear forces, that is the capacities of the models, and the maximum seismic coefficients, $c_{n}$, calculated according to Eq. (3). Since the volumes of the buttresses are taken equal in this group calculations and the base model is the same, the weights, $W_{\text {model }}$, of the models are equal. Therefore, $W_{\text {model }}$ in the calculation of $c_{n}{ }^{\prime}$ s is equal for all models and its value is $793.93 \mathrm{kN}$. In the table, the ratios of the capacities of the models to the capacity of the rectangular buttressed model are also given. It can be seen from the table that model having curvilinear concave buttresses has the highest seismic capacity, and the model with semi-cylindrical buttresses has the lowest capacity. The 
table clearly shows how their "forms" affect the seismic resistance of the structure, even though buttresses of equal volume are considered.

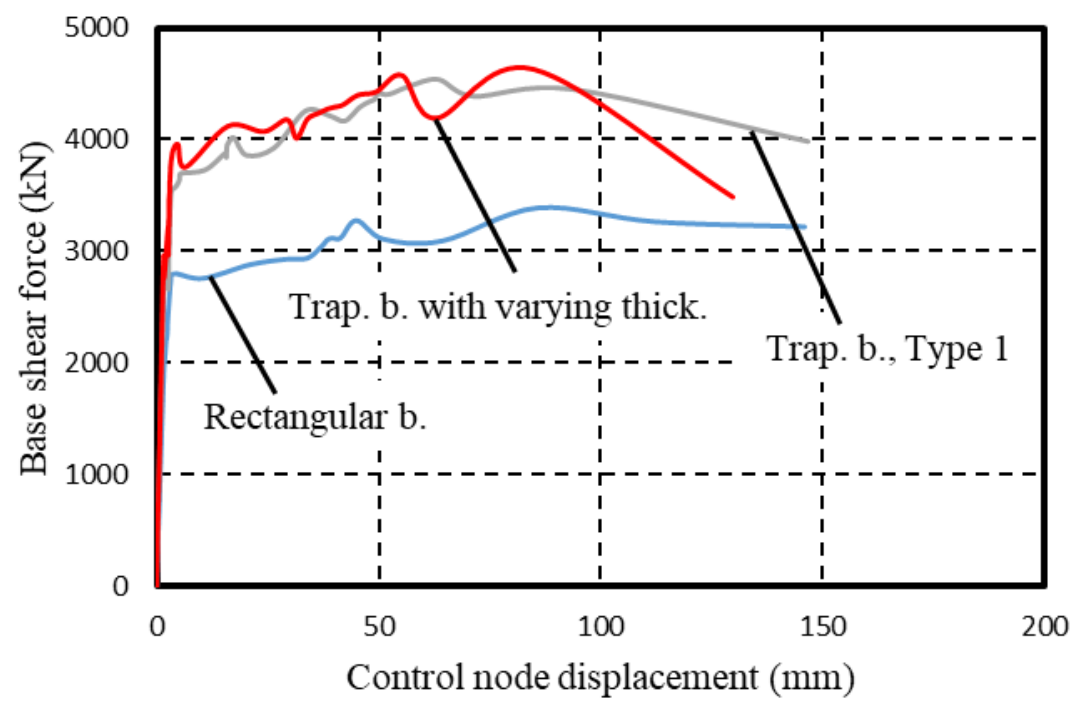

Fig. 17 Capacity curve of the model having trapezoidal buttresses with varying thickness, and comparison with the capacity curves of the rectangular and trapezoidal (Type 1) buttressed models

If the capacity curves' a general assessment is made, the first thing observed is that they are not smooth. This is quite normal, because damages occur to the models with increasing horizontal load, and the curves naturally progress in a non-smooth way as these damages spread and new damages occur. The curves of all models begin with a high slope zone. This is the stage, where there is no damage to the models yet, so the lateral stiffness is highest. After this zone, a sudden drop in stiffness takes place due to the initial cracking. The curves then exhibit a second climbing zone, the slope of which gradually decreases, and reaches a maximum. Then the curves descend in general and collapse is reached at the end of the zone. Some of them show a slight recovery in the last part of this descending zone. 
Table 6 A collective comparison of transverse seismic resistance of the models in first group analyses

\begin{tabular}{|c|c|c|c|}
\hline Buttress form & $\begin{array}{l}\text { Max. base shear } \\
\text { force, } R_{\max }(\mathrm{kN})\end{array}$ & $\begin{array}{c}\text { Max. seism. coeff., } \\
c_{n}=R_{\text {max }} / W_{\text {model }}\end{array}$ & $R_{\max } / R_{\max , \text { rec }}$ \\
\hline Rectangular (Fig. 8a) & 3382.91 & 4.26 & 1 \\
\hline Triangular (Fig. 8b) & 4939.04 & 6.22 & 1.46 \\
\hline Trapezoidal (Fig. 8c, Type 1) & 4533.40 & 5.71 & 1.34 \\
\hline Trapezoidal (Fig. 8c, Type 2) & 4738.48 & 5.97 & 1.40 \\
\hline Trapezoidal (Fig. 8c, Type 3) & 4233.61 & 5.33 & 1.25 \\
\hline Two-stepped (Fig. 8d $\mathrm{d}_{1}$ ) & 4311.21 & 5.43 & 1.27 \\
\hline Three-stepped (Fig. 8d $\mathrm{d}_{2}$ ) & 4320.49 & 5.44 & 1.28 \\
\hline First type combined (Fig. 8e $\mathrm{e}_{1}$ ) & 3927.07 & 4.95 & 1.16 \\
\hline Second type combined (Fig. 8e e $_{2}$ & 4385.54 & 5.52 & 1.30 \\
\hline Third type combined (Fig. 8e 3 ) & 4890.22 & 6.16 & 1.45 \\
\hline Curvilinear concave (Fig. 8f $f_{1}$ ) & 5520.29 & 6.95 & 1.63 \\
\hline Curvilinear convex (Fig. 8f $\mathrm{f}_{2}$ ) & 4226.03 & 5.32 & 1.25 \\
\hline Semi-cyl. (Fig. 8g $g_{1}$ ) & 2739.54 & 3.45 & 0.81 \\
\hline Triang. pri. (Fig. $8 \mathrm{~g}_{2}$ ) & 3149.55 & 3.97 & 0.93 \\
\hline Truncated half-conic (Fig. $8 \mathrm{~g}_{3}$ ) & 3534.11 & 4.45 & 1.05 \\
\hline Trap. with vary. thick. (Fig. 8h) & 4636.14 & 5.84 & 1.37 \\
\hline
\end{tabular}

\subsubsection{Second group analyses}

As for the analyses in this second group, here simply the bottom depths and thicknesses of buttresses are taken equal to each other. The reason for taking the buttress dimensions in this way is to determine how the buttress form affects the lateral seismic resistance of the structure if the base area of the buttresses is limited. It should be noted that, only in semi-cylindrical and truncated half-conic buttresses, Fig. $8 \mathrm{~g}_{1}$ and $\mathrm{g}_{3}$, although the depth condition can be met, the thickness condition at the bottom cannot be realized due to their geometry. The dimensions of the buttresses in this group analyses are given in Table 7. The buttresses that need to be designed (arranged) have been designed with the same considerations expressed in the first group analyses. The table also presents the volumes of the buttresses and the ratio of the volume of each buttress to the volume of the rectangular buttress.

The results of the analyses, that is, the capacity curves of the models are presented in Fig. 18. It can be seen that the curves of the semi-cylindrical and truncated half-conic buttressed models are at 
Table 7 Dimensions of the buttresses in the second group analyses

\begin{tabular}{|c|c|c|c|}
\hline Buttress form & Dimensions (in meter) & $\begin{array}{l}\text { Volume, } \\
V\left(\mathrm{~m}^{3}\right)\end{array}$ & $\begin{array}{l}\text { Vol. ratio, } \\
V / V_{\text {rec }}\end{array}$ \\
\hline Rectangular (Fig. 8a) & $h=11.10, t_{\mathrm{rec}}=1.35, d_{\mathrm{rec}}=2.20$ & 32.97 & 1 \\
\hline Triangular (Fig. 8b) & $h=11.10, t=1.35, d_{\mathrm{tri}}=2.20$ & 16.48 & 0.50 \\
\hline Trapezoidal (Fig. 8c) & $h=11.10, t=1.35, d_{\mathrm{tra}, \mathrm{b}}=2.20, d_{\mathrm{tra}, \mathrm{t}}=0.73$ & 21.95 & 0.67 \\
\hline $\begin{array}{l}\text { Two-stepped } \\
\left.\text { (Fig. } 8 d_{1}\right)\end{array}$ & $\begin{array}{l}h=11.10, t=1.35, d_{\mathrm{st}, 2, \mathrm{u}}=1.10 \\
d_{\mathrm{st}, 2, l}=2.20, h_{\mathrm{st}, 2, \mathrm{u}}=5.55, h_{\mathrm{st}, 2, l}=5.55\end{array}$ & 24.73 & 0.75 \\
\hline $\begin{array}{l}\text { Three-stepped } \\
\left.\text { (Fig. } 8 \mathrm{~d}_{2}\right)\end{array}$ & $\begin{array}{l}h=11.10, t=1.35, d_{\mathrm{st}, 3, \mathrm{u}}=0.73, d_{\mathrm{st}, 3, \mathrm{i}}=1.47 \\
d_{\mathrm{st}, 3 l}=2.20 \\
h_{\mathrm{st}, 3, \mathrm{u}}=3.70, h_{\mathrm{st}, 3, \mathrm{i}}=3.70, h_{\mathrm{st}, 3, l}=3.70\end{array}$ & 21.98 & 0.67 \\
\hline $\begin{array}{l}\text { First type combined } \\
\left.\text { (Fig. } 8 \mathrm{e}_{1}\right)\end{array}$ & $\begin{array}{l}h=11.10, t=1.35, d_{\text {com }, 1, \mathrm{~b}}=2.20 \\
h_{\text {com }, 1, \mathrm{u}}=5.55, h_{\text {com }, 1, l}=5.55\end{array}$ & 24.73 & 0.75 \\
\hline $\begin{array}{l}\text { Second type combined } \\
\text { (Fig. } 8 \mathrm{e}_{2} \text { ) }\end{array}$ & $\begin{array}{l}h=11.10, t=1.35, d_{\mathrm{com}, 2, \mathrm{~b}}=2.20, d_{\mathrm{com}, 2, \mathrm{u}}= \\
1.10, h_{\mathrm{com}, 2, \mathrm{u}}=5.55, h_{\mathrm{com}, 2, l}=5.55\end{array}$ & 20.60 & 0.63 \\
\hline $\begin{array}{l}\text { Third type combined } \\
\text { (Fig. } 8 \mathrm{e}_{3} \text { ) }\end{array}$ & $\begin{array}{l}h=11.10, t=1.35, d_{\mathrm{com}, 3, \mathrm{~b}}=2.20, d_{\mathrm{com}, 3, \mathrm{i}}= \\
1.10, h_{\mathrm{com}, 3, \mathrm{u}}=3.70, h_{\mathrm{com}, 3, \mathrm{i}}=3.70, h_{\mathrm{com}, 3, l}= \\
3.70\end{array}$ & 16.48 & 0.50 \\
\hline $\begin{array}{l}\text { Curvilinear concave } \\
\text { (Fig. } 8 \mathrm{f}_{1} \text { ) }\end{array}$ & $h=11.10, t=1.35, d_{\text {cur }, \mathrm{cv}, \mathrm{b}}=2.20$ & 10.99 & 0.33 \\
\hline $\begin{array}{l}\text { Curvilinear convex (Fig. } \\
8 \mathrm{f}_{2} \text { ) }\end{array}$ & $h=11.10, t=1.35, d_{\mathrm{cur}, \mathrm{cx}, \mathrm{b}}=2.20$ & 21.98 & 0.67 \\
\hline Semi-cyl. (Fig. 8g g $_{1}$ & $h=11.10, d_{\text {semi cyl }}=2.20$ & 84.39 & 2.56 \\
\hline Triang. pri. (Fig. $8 \mathrm{~g}_{2}$ ) & $h=11.10, t_{\text {tri pri }}=1.35, d_{\text {tri pri }}=2.20$ & 16.48 & 0.50 \\
\hline $\begin{array}{l}\text { Truncated half-conic } \\
\text { (Fig. } 8 \mathrm{~g}_{3} \text { ) }\end{array}$ & $h=11.10, d_{\mathrm{tr}, \mathrm{ht}, \mathrm{con}, \mathrm{b}}=2.20, d_{\mathrm{tr}, \mathrm{hf}, \mathrm{con}, \mathrm{t}}=1.10$ & 49.23 & 1.49 \\
\hline $\begin{array}{l}\text { Trapez. with varying } \\
\text { thickness (Fig. 8h) }\end{array}$ & $\begin{array}{l}h=11.10, d_{\text {tra, var, } \mathrm{b}}=2.20, d_{\text {tra,var } \mathrm{t}}=1.10 \\
t_{\text {tra,var, } \mathrm{b}}=1.35, t_{\text {tra, var, } \mathrm{t}}=0.68\end{array}$ & 19.23 & 0.58 \\
\hline
\end{tabular}

the top, that of the triangular prism buttressed model is at the bottom, and those of the others are in between. In Table 8, the capacities, weights, maximum seismic coefficients and the ratios of capacities of the models to the capacity of the rectangular buttressed model are given. When the semicylindrical and truncated half-conic buttressed models are excluded (because it was stated above that the buttresses in these models cannot meet the thickness requirement due to their geometry) and a comparison is made between the other models, it is seen that the three-stepped buttressed model has the highest seismic resistance, and the triangular prism buttressed one has the lowest resistance. The curvilinear concave buttressed model, which gave the highest resistance in the first group analyses, 
gave the lowest seismic resistance after the triangular prism buttressed model in the analyses in this group. When evaluating the results of the trapezoidal, stepped and combined buttressed models, it should not be forgetten that their buttresses were completely arranged by ourselves, adhering only to the condition of "equal base depth". In these models when the design of the buttresses is changed, it is obvious that the results will also change to a certain extent.

Table 8 A collective comparison of transverse seismic resistance of the models in second group analyses

\begin{tabular}{|c|c|c|c|c|}
\hline Buttress form & $\begin{array}{c}\text { Max. base shear } \\
\text { force, } \\
R_{\max }(\mathrm{kN}) \\
\end{array}$ & $\begin{array}{c}W_{\text {model }} \\
(\mathrm{kN})\end{array}$ & $\begin{array}{c}\text { Max. seism. } \\
\text { coeff., } c_{n}= \\
R_{\max } / W_{\text {model }} \\
\end{array}$ & $R_{\max } / R_{\max , \text { rec }}$ \\
\hline Rectangular (Fig. 8a) & 3382.91 & 793.93 & 4.26 & 1 \\
\hline Triangular (Fig. 8b) & 3322.10 & 600.94 & 5.53 & 0.982 \\
\hline Trapezoidal (Fig. 8c) & 3366.28 & 665.40 & 5.06 & 0.995 \\
\hline Two-stepped (Fig. 8d d $_{1}$ & 3334.46 & 698.12 & 4.78 & 0.986 \\
\hline Three-stepped (Fig. 8d d & 3706.03 & 665.40 & 5.57 & 1.096 \\
\hline First type comb. (Fig. 8e $\mathrm{e}_{1}$ ) & 3445.65 & 698.12 & 4.94 & 1.019 \\
\hline Second type comb. (Fig. 8e e $_{2}$ ) & 3549.40 & 649.04 & 5.47 & 1.049 \\
\hline Third type comb. (Fig. 8e $\mathrm{e}_{3}$ ) & 3224.28 & 600.94 & 5.37 & 0.953 \\
\hline Curv. concave (Fig. 8f 1 ) & 3011.37 & 536.73 & 5.61 & 0.890 \\
\hline Curv. convex (Fig. 8f $\left.f_{2}\right)$ & 3492.15 & 665.40 & 5.25 & 1.032 \\
\hline Semi-cyl. (Fig. 8g g $_{1}$ ) & 4468.32 & 1394.54 & 3.20 & 1.321 \\
\hline Triang. pri. (Fig. $8 \mathrm{~g}_{2}$ ) & 2843.30 & 600.94 & 4.73 & 0.840 \\
\hline Trunc. half-conic (Fig. $8 g_{3}$ ) & 4139.76 & 983.23 & 4.21 & 1.224 \\
\hline Trap. with vary. thick. (Fig. 8h) & 3324.09 & 633.51 & 5.25 & 0.983 \\
\hline
\end{tabular}

To sum up, the calculations show that the lateral seismic resistance of structures supported by buttresses of different forms with equal base depths are at different levels, as expected. However, when the results of the two groups of analysis are compared, Table 6 and Table 8 , it is seen that the effect of the buttress form on seismic resistance in the case of this second group is not as high as in the first group. In addition, it should be noted that although the semi-circular buttress provided the highest seismic resistance to the structure in the second group calculations, in this case its volume and therefore the amount of material used is considerably higher than the other buttresses. 

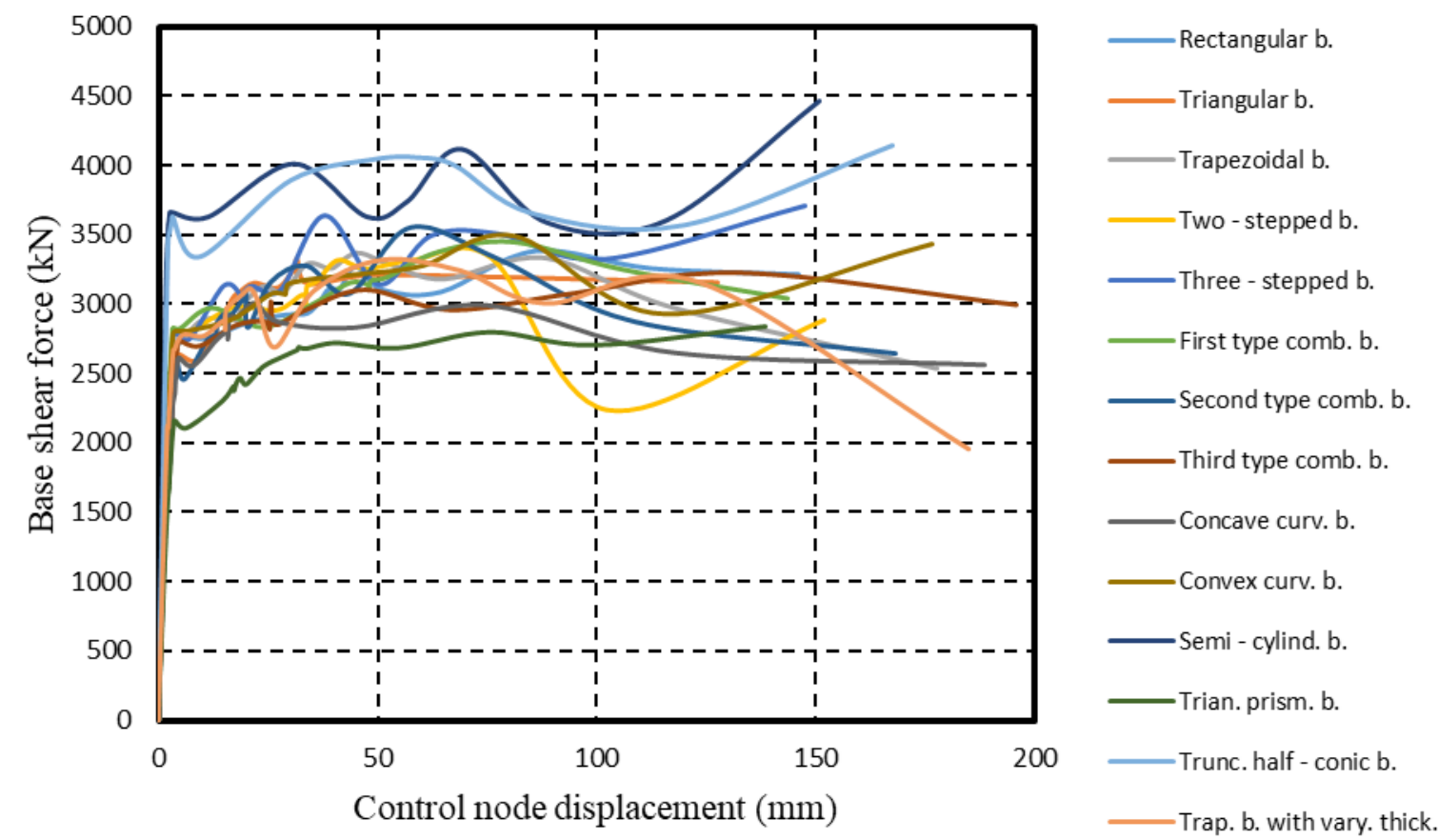

Fig. 18 Capacity curves of the models in second group analyses

\section{Conclusions and future works}

In this study, the effect of buttress form on transverse seismic resistance of high masonry walls was investigated. For this purpose, from a real historical masonry structure, a calculation model and a basic model were created. As analysis method, nonlinear static analysis method was used and calculations were carried out with the Abaqus program. Firstly, the effect of buttress depth on transverse seismic resistance of the structure was investigated by changing the buttress depth in the calculation model. Then, two groups of analyses were performed on the models obtained by mounting different buttress forms to the basic model. For buttresses, a rich variety of forms was considered. The salient results can be summarised as follows.

a) Buttress depth is an important parameter on the transverse seismic resistance of high masonry walls, and thus building-type masonry structures. In rectangular buttressed structures, the maximum seismic capacity of the structure is almost linearly related to the buttress depth. 
b) In the case of buttresses of equal volume (first group analyses), the form has a strong influence on the seismic resistance of the structure. Among the buttresses considered, the curvilinear concave buttress provides the highest seismic resistance to the structure, while the semicircular buttress gives the lowest support. The slope of trapezoidal buttress has a noticeable effect on the seismic capacity of the structure. Provided that depths and heights of its parts are arranged harmoniously, the behavior of a stepped buttress approaches that of a triangular buttress, as the number of steps increases. Arrangement of a combined buttress affects the level of support that this buttress will provide to the structure.

c) In the case of buttresses with equal base depth and thickness (second group analyses), the form again has an effect on the capacity. However, the effect of the form in this case is not as striking as in the case of equal-volume buttresses.

d) The general conclusion of the study is that, no matter what form of buttress used by the ancient builders, their high awareness of the structural significance of the buttress is sufficient for us to remember them with respect and admiration. If they not had this insight, there would have been no, for example, magnificent Ottoman mosques and grandiose Gothic cathedrals that fascinate us today.

As mentioned earlier, the effect of buttress form on seismic behavior and resistance in squat historic masonry structures is investigated in an ongoing study. Apart from this, buttresses in the form of a special mathematical curve, tower-like buttresses (like those with box cross-section and ringsection), and buttresses stepped in two directions can also be studied. In addition, albeit they act like tension ropes, by taking inspiration from buttress root shapes of some trees, studies can be made on the optimum buttress forms. These are left to future studies.

\section{References}

Abaqus, Theory manual. Version 6.14-5; 2014.

Angelillo M, (Ed.), (2014) Mechanics of masonry structures. CISM International Centre for Mechanical Sciences, DOI 10.1007/ 978-3-7091-1774-3, Vienna, Springer.

Antalya Foundations Regional Directorate Archieve. 
Bartholomew A, (1840) On buttresses, pinnacles \&c, The Civil Engineer and Architect's Journal. Scientific and Railway Gazette, Volume III, London.

Chávez MM, Peña F, (2019) Influence of the Thickness of Vaults and Buttresses in the Structural Response of Mexican Colonial Temples. Structural Analysis of Historical Constructions, R. Aguilar et al. (Eds.), RILEM 2019, pp. 862-870.

De Lorenzis L, Dimitri R, Ochsendorf J, (2012b) Structural study of masonry buttresses: the stepped form. Proceedings of the Institution of Civil Engineers - Structures and Buildings 165(9): 499-521.

De Lorenzis L, Dimitri R, Ochsendorf J, (2012a) Structural study of masonry buttresses: the trapezoidal form. Proceedings of the Institution of Civil Engineers - Structures and Buildings 165(9): 483-498.

DeJong MJ, (2009) Seismic assessment strategies for masonry structures. PhD Thesis, Massachusetts Institute of Technology.

Endo Y, Pelà L, Roca P, (2016) Review of different pushover analysis methods applied to masonry buildings and comparison with nonlinear dynamic analysis. Journal of Earthquake Engineering Vol. 21, No. 8, pp. 1234-1255.

Freely J, (2011) A History of Ottoman Architecture. WIT Press, Great Britain, 437 pages.

Fuentes P, (2018) Mechanics of flying buttresses: The case of the Cathedral of Mallorca. Journal of Mechanics of Materials and Structures Vol. 13, No. 5, pp. 617-630.

García N, Meli R, (2009) On Structural Bases for Building the Mexican Convent Churches From the Sixteenth Century. International Journal of Architectural Heritage Vol. 3, No. 1, pp. 24-51.

Giordano A, Mele E, De Luca A, (2002) Modelling of historical masonry structures: comparison of different approaches through a case study. Engineering Structures Vol. 24, Issue 8, pp. 1057-1069.

Heyman J, (1997) The Stone Skeleton: Structural Engineering of Masonry Architecture. Cambridge University Press, Reprint edition, 172 pages.

Hognestad E, (1951) A study of combined bending and axial load in reinforced concrete members. University of Illinois Bulletin Vol. 49, No. 22, Urbana, Illinois, 128 pages.

Huerta S, (1990) Diseño estructural de arcos, bóvedas y cúpulas en España, ca. 1500-ca. 1800. PhD thesis, Univ. Politécnica de Madrid, E.T.S. de Arquitectura, Madrid, Spain (in Spanish).

Huerta S, (2004) Arcos, bo'vedas y cu' pulas: geometri'a y equilibrio en el ca'lculo tradicional de estructuras de fa'brica. Instituto Juan de Herrera, Escuela Te'cnica Superior de Arquitectura de Madrid, Spain (in Spanish).

Huerta S, (2010) The safety of masonry buttresses. Proceedings of the Institution of Civil Engineers, Engineering History and Heritage 163(1):3-24.

Illampas R, Ioannou I, Lourenço PB, (2020) Seismic appraisal of heritage ruins: The case study of the St. Mary of Carmel church in Cyprus. Engineering Structures Vol. 224, Article 111209. 
İzol R, Gürel MA, Pekgökgöz RK, Avcil F, (2019) Out-of-plane seismic resistance of high masonry walls having rectangular buttresses (in Turkish). Journal of the Faculty of Engineering and Architecture of Gazi University Vol. 34, No. 2, pp. 1007-1023.

Karanikoloudis G, Lourenço PB, Alejo LE, Mendes N, (2020) Lessons from Structural Analysis of a Great Gothic Cathedral: Canterbury Cathedral as a Case Study. International Journal of Architectural Heritage https://doi.org/10.1080/15583058.2020.1723736, pp. 1-30.

Karimi N, Aboue R, Heydari D, (2016) Typology and Developments in buttresses from the beginning to the historical era in Iranian architecture. Bagh-e Nazar, Journal of art, architecture and urban studies at NAZAR research center Vol. 13, No. 40, pp. 57-72.

Korkmaz Ş, (2019) Determination of thermal conductivity, physical and mechanical properties of brick materials used in historical buildings. Dep. of Civil Eng., Graduate School of Natural and Applied Sciences, Süleyman Demirel University, Isparta, 241 pages, (in Turkish).

Makris N, Alexakis H, (2015) Limit equilibrium analysis of masonry buttresses and towers under lateral and gravity loads. Archive of Applied Mechanics 85:1915-1940.

Mark R, (1984) Experiments in Gothic Structure. The MIT Press, 152 pages.

Massicotte B, Elwi AE, MacGregor JG, (1990) Tension-stiffening model for planar reinforced concrete members. Journal of Structural Engineering, ASCE Vol. 116, No. 11, pp. 3039-3058.

Moore CH, (1899) Development and Character of Gothic Architecture. 2. Edition, The Macmillan Company, New York, 454 pages.

Ochsendorf JA, Hernando JI, Huerta S, (2004) Collapse of masonry buttresses. Journal of Architectural Engineeing, ASCE Vol. 10, No. 3, 88-97.

Ochsendorf J, De Lorenzis L, (2008) Failure of rectangular masonry buttresses under concentrated loading. Proceedings of the Institution of Civil Engineers, Structures and Buildings 161(5):265-276.

Roca P, Cervera M, Pelà L, Clemente R, Chiumenti M, (2013) Continuum FE models for the analysis of Mallorca Cathedral. Engineering Structures 46:653-670.

Sanabria SL, (1982) The Mechanization of Design in the 16th Century: The Structural Formulae of Rodrigo Gil de Hontañón. Journal of the Society of Architectural Historians Vol. 41, No. 4, pp. 281293.

Smith TR, (1880) Architecture: Gothic and Renaissance. R. Clay. Sons. and Taylor, London, 236 pages.

Stierlin H, (1997) Greece, From Mycenae to the Parthenon. Benedikt Taschen Verlag GmbH, Köln, 235 pages.

Tomaževič M, (1999) Earthquake-Resistant Design of Masonry Buildings. Imperial College Press, London, 268 pages.

Ungewitter G, Mohrmann K, (1890) Lehrbuch der Gotischen Konstruktionen. 3rd edition, 2 volumes, T. O. Weigel Nachfolger, Leipzig. 
Url-1:

https://commons.wikimedia.org/wiki/File:ZOCALO_DE_SAN_CRISTOBAL_DE_LAS_CASAS_C HIAPAS.jpg, Date accessed: 20.01.2020.

Url-2: https://commons.wikimedia.org/wiki/File:Exterior of Westminster Abbey 20160816.jpg, Date accessed: 06.02.2021.

Url-3: https://commons.wikimedia.org/wiki/Category:San_Frediano_in_Cestello_(Florence), Date accessed: 13.01.2021.

Url-4: http://konyalife.com.tr/haber/anadolunun-en-buyuk-hani-zazadin-han-2476.html, Date accessed: 26.02 .2020 .

Url-5:https://www.amazon.com/Experiments-Gothic-Structure-Robert-Mark/dp/0262630958, Date accessed: 08.04.2020.

Valente M, Milani G, (2016) Non-linear dynamic and static analyses on eight historical masonry towers in the North-East of Italy. Engineering Structures 114:241-270. 


\section{Figures}

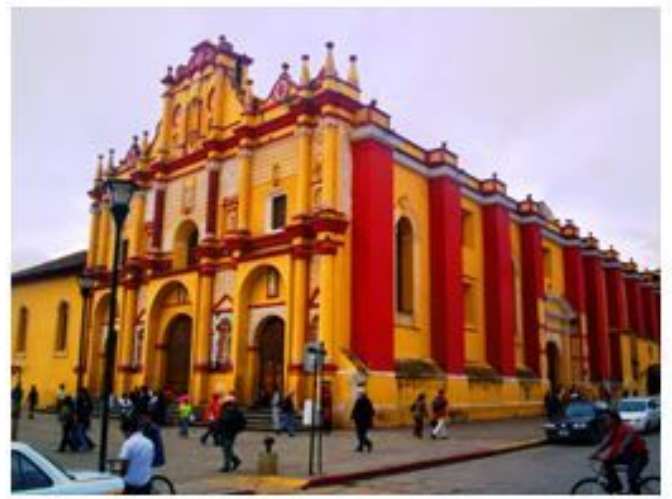

a) Rectangular buttresses of San Cristobal Cathedral, (Las Casas, Mexico), (Url-1)

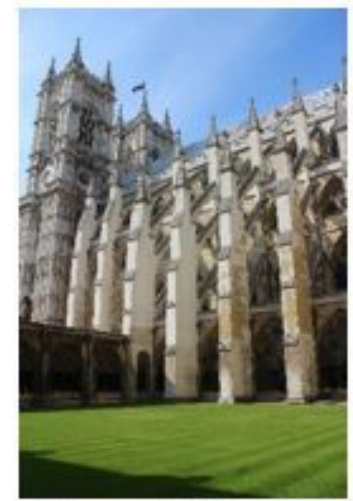

c) Stepped buttresses of Westminster Abbey, (London, England), (Url-2)

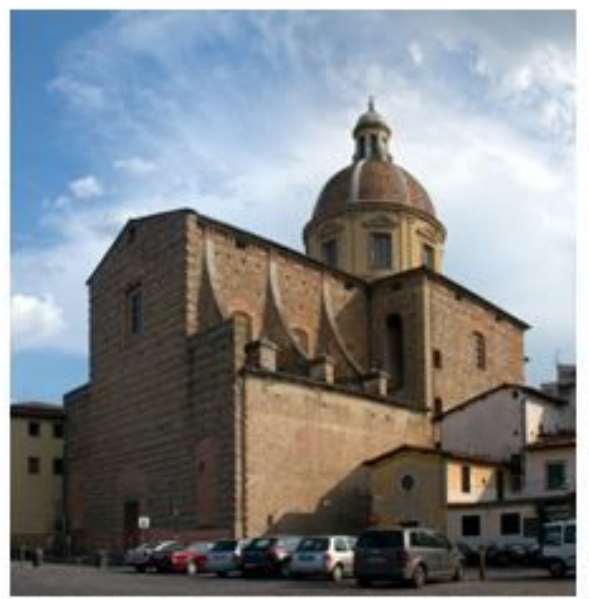

e) Curvilinear buttresses of San Frediano Church, (Florence, Italy), (Url-3)

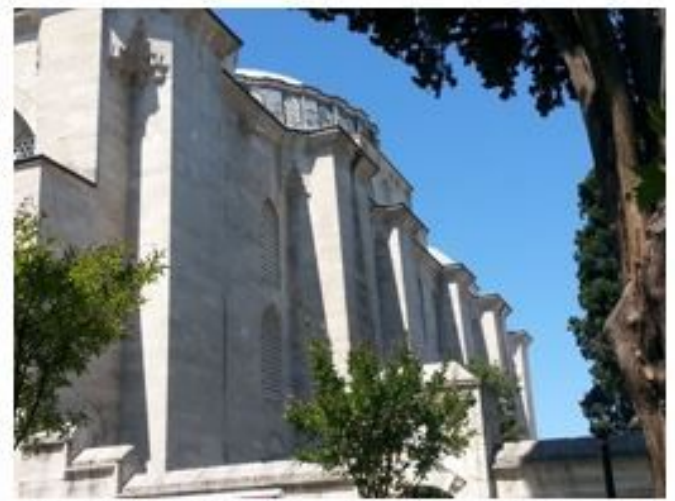

b) Trapezoidal buttresses of Qibla wall of Süleymaniye Mosque (İstanbul, Turkey), (Photo: Authors)

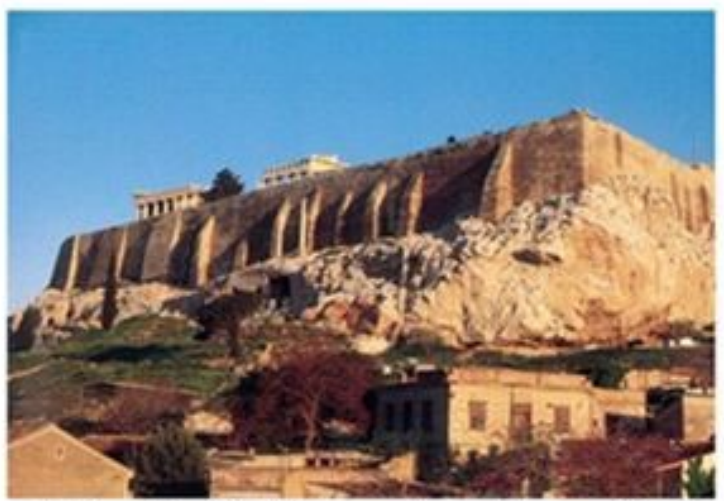

d) Combined buttresses of retaining walls of Acropolis of Athens, (Athens, Greece),

(Stierlin, 1997)

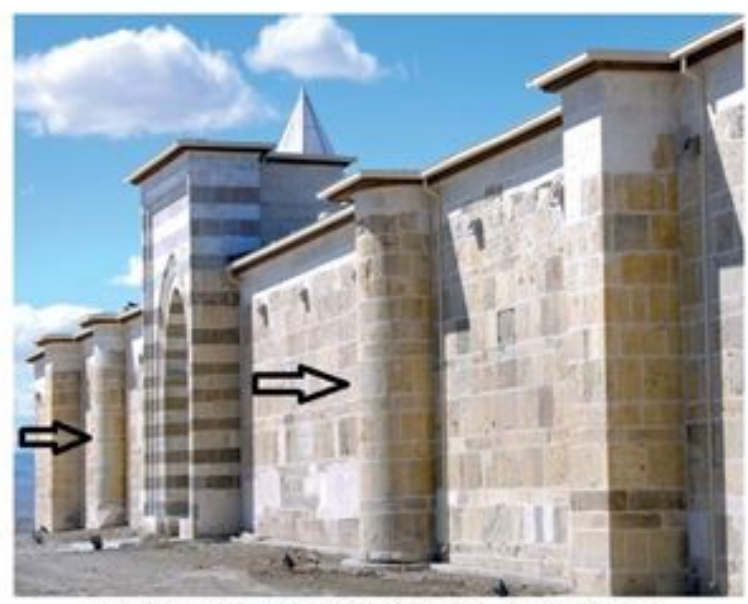

f) Semi-circular buttresses of Zazadin Han (Inn), (Konya, Turkey), (Url-4)

\section{Figure 1}

Buttress examples from historical masonry architecture 


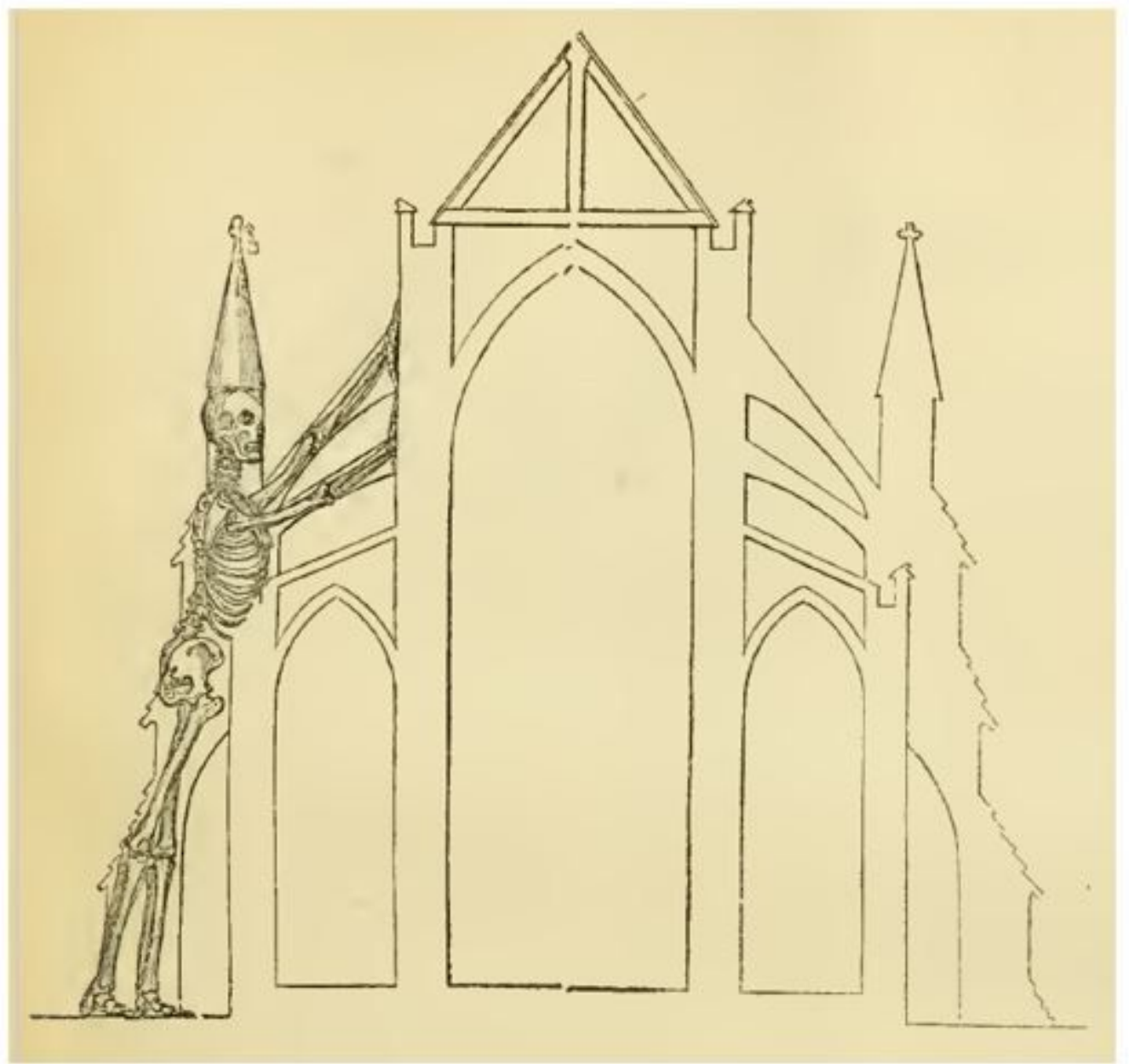

\section{Figure 2}

A leaning human model representing the cooperation of flying buttress, pinnacle and external buttress trio in supporting a Gothic cathedral, Bartholomew, (1840) 


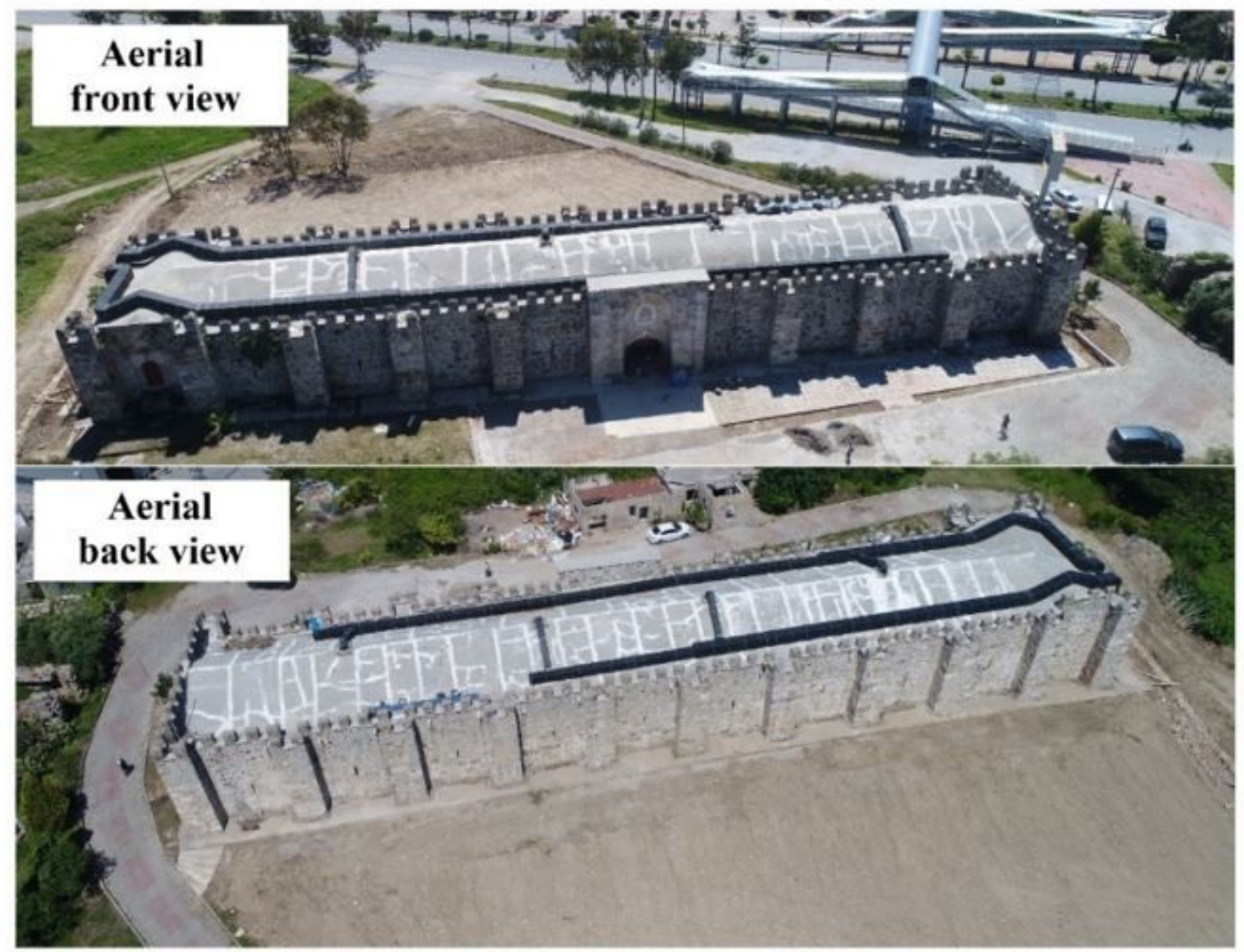

Figure 3

Şarapsa Han, (Photo: Authors)

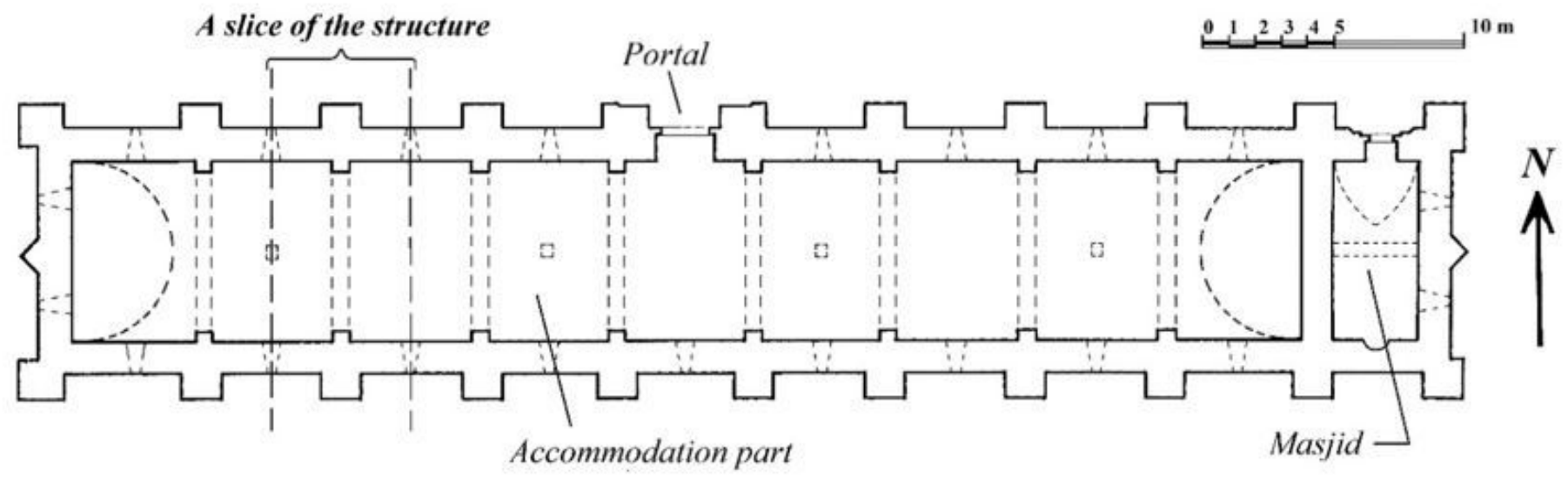

Figure 4 


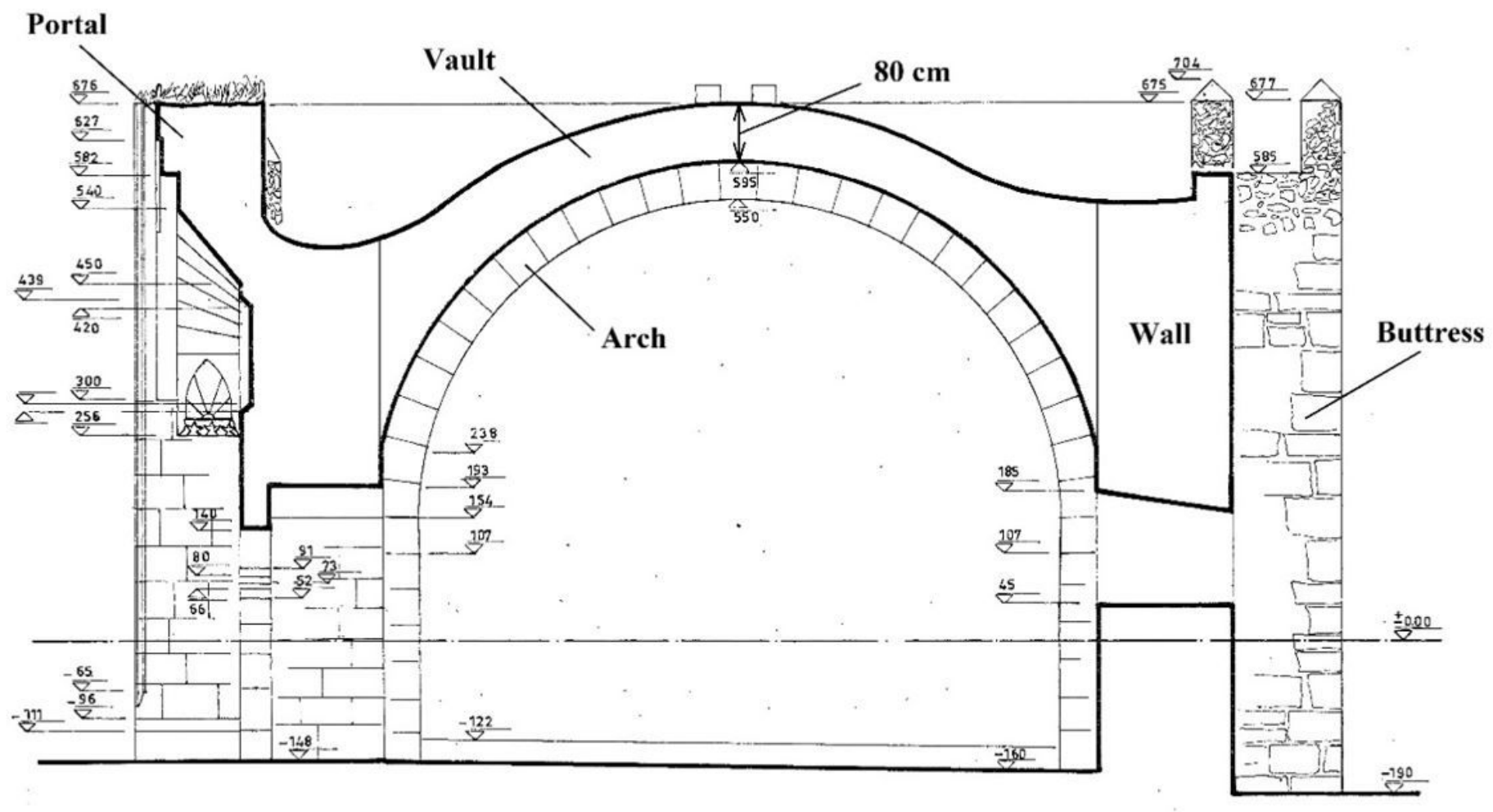

Figure 5

Transverse section taken from the portal of the Han, (measures are in $\mathrm{cm}$ ), (Used with the permission of Antalya Foundations Regional Directorate) 
a)

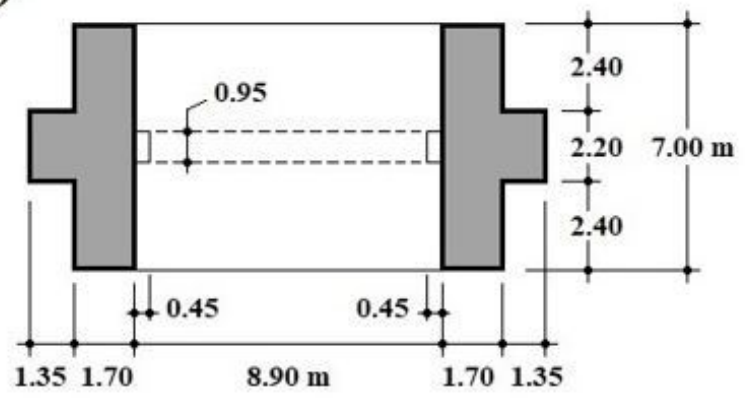

Plan

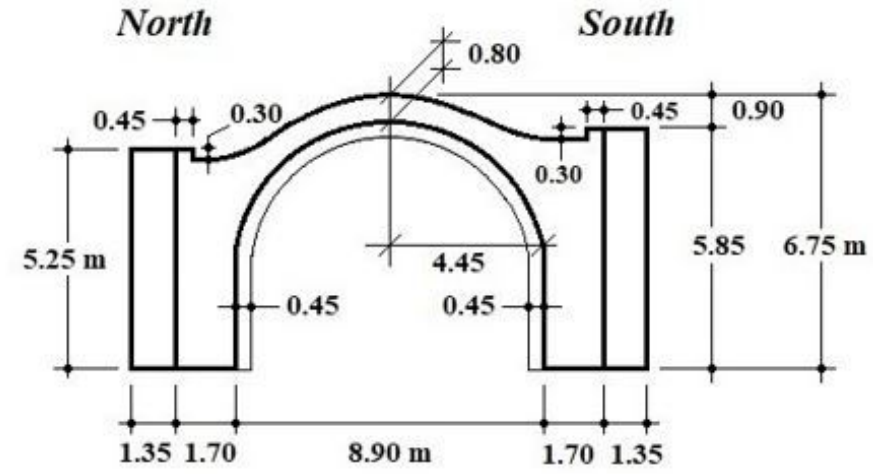

Elevation b)

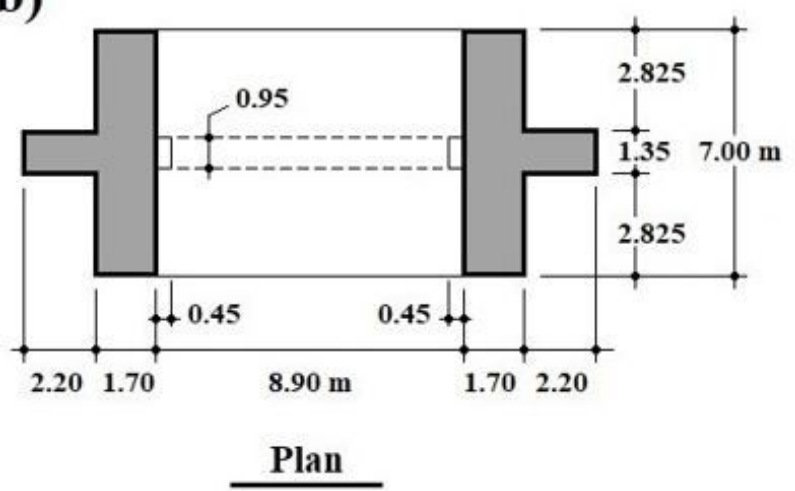

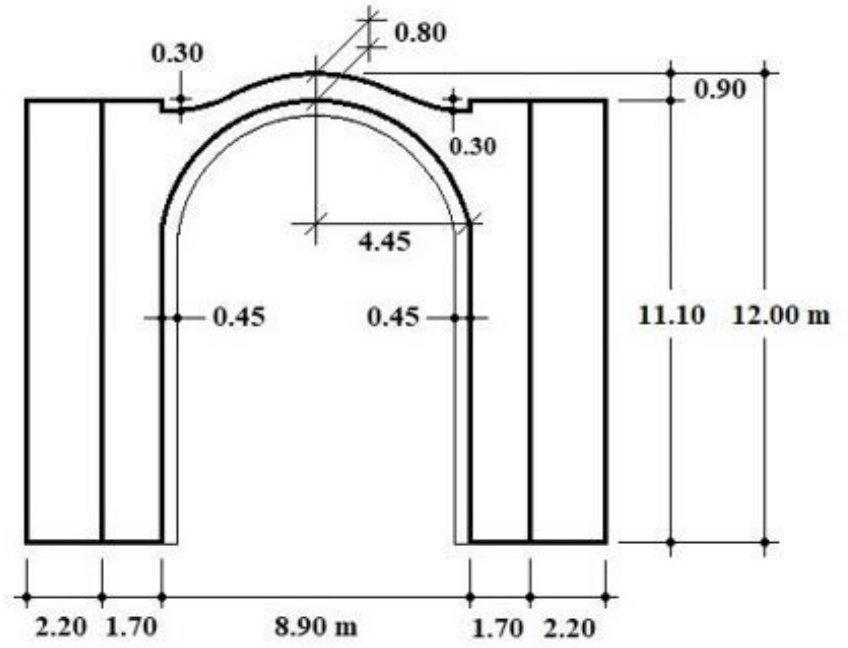

Elevation

Figure 6

Models of the Şarapsa Han: a) Real model, b) Modified model used in calculations (Drawings are not to scale) 


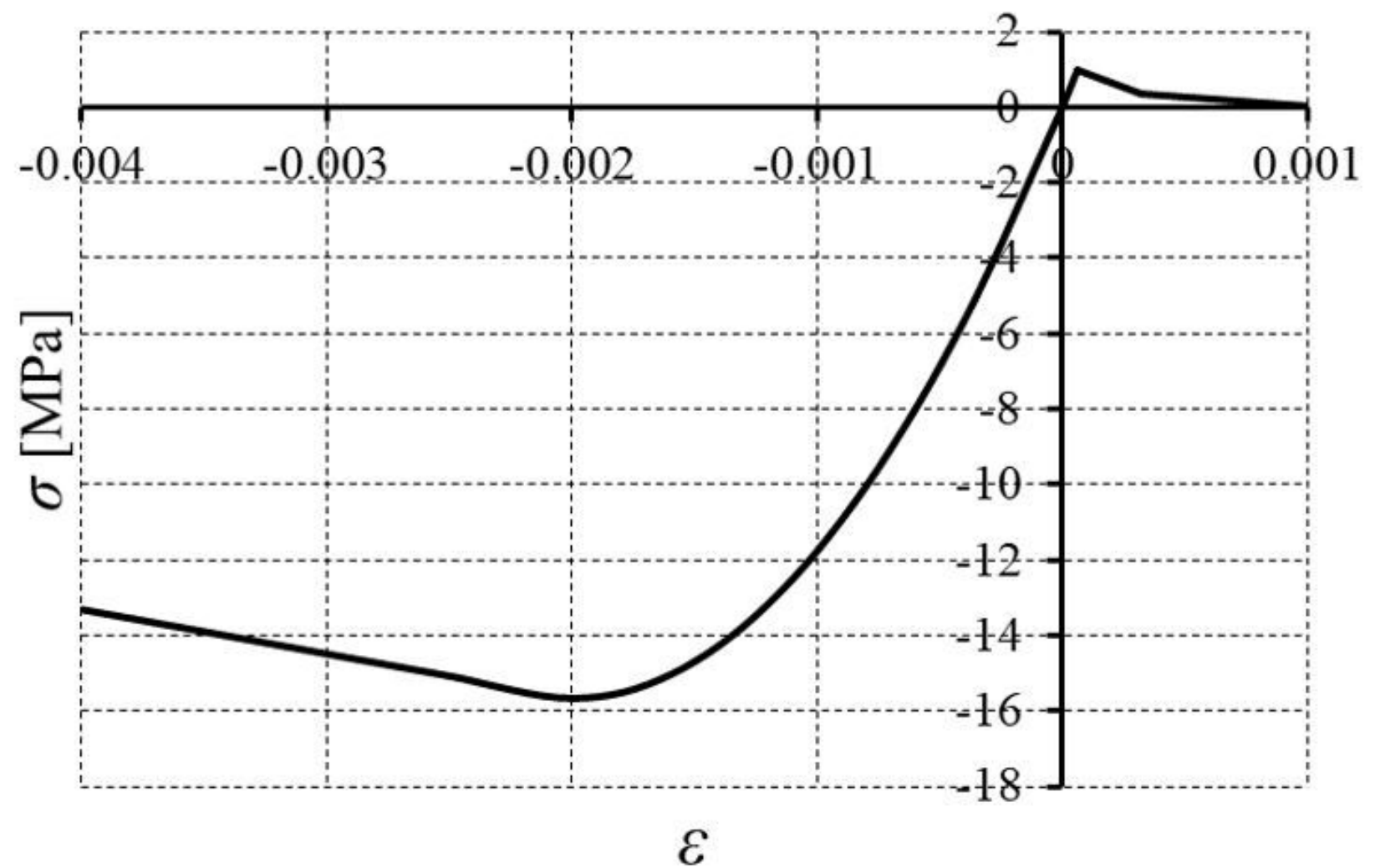

Figure 7

The artificially formed uniaxial $\sigma-\varepsilon$ graphic of the homogenized masonry material of the Han 


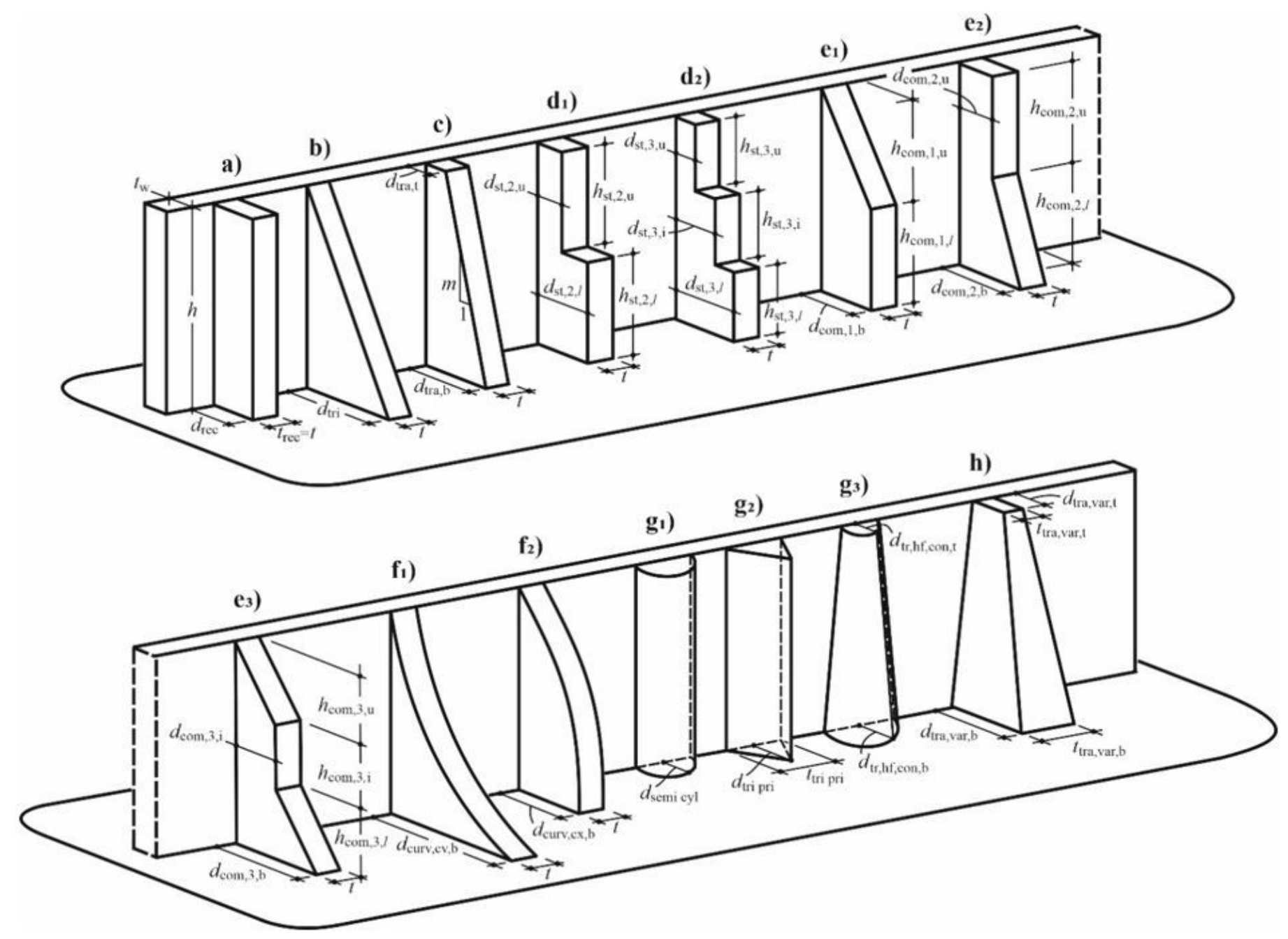

Figure 8

Buttress forms considered in the analyses: a) rectangular b., b) triangular b., c) trapezoidal b., d1) twostepped b., d2) three-stepped b., e1) first type combined b., e2) second type combined b., e3) third type combined b., f1) concave curvilinear b., f2) convex curvilinear b., g1) semi-cylindrical b., g2) triangular prism b., g3) truncated half-conic b., and h) trapezoidal buttress with varying thickness 


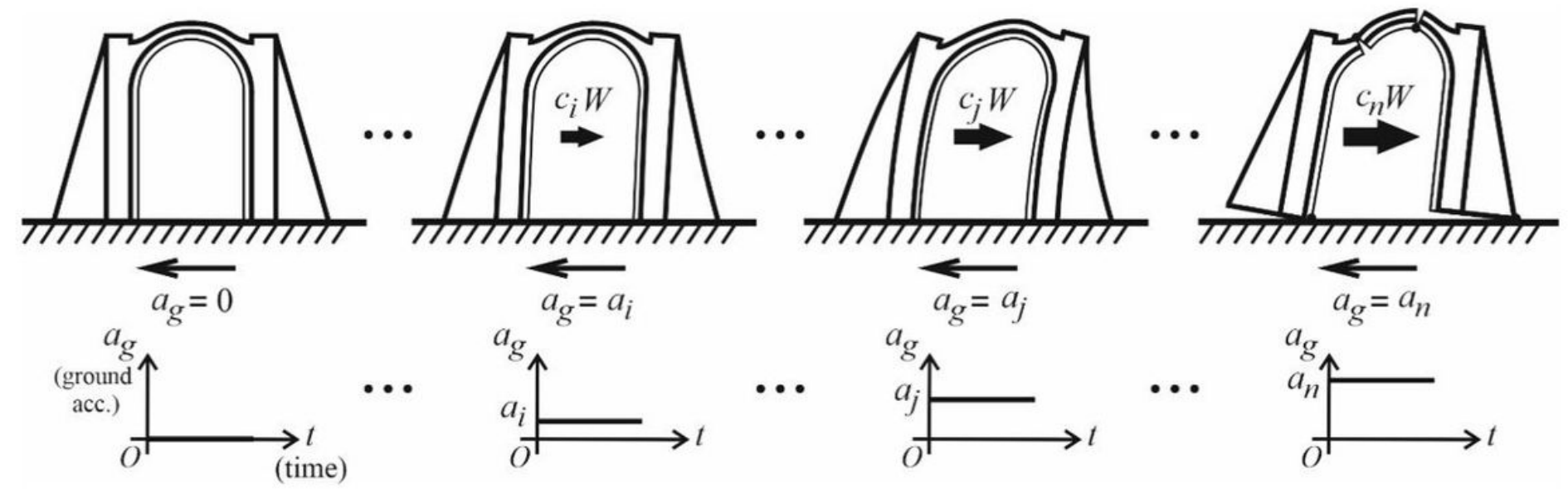

Figure 9

A schematic representation of the increasing lateral forces and failure mechanism occuring in triangular buttressed model due to the gradually increasing unidirectional horizontal earthquake ground motion 

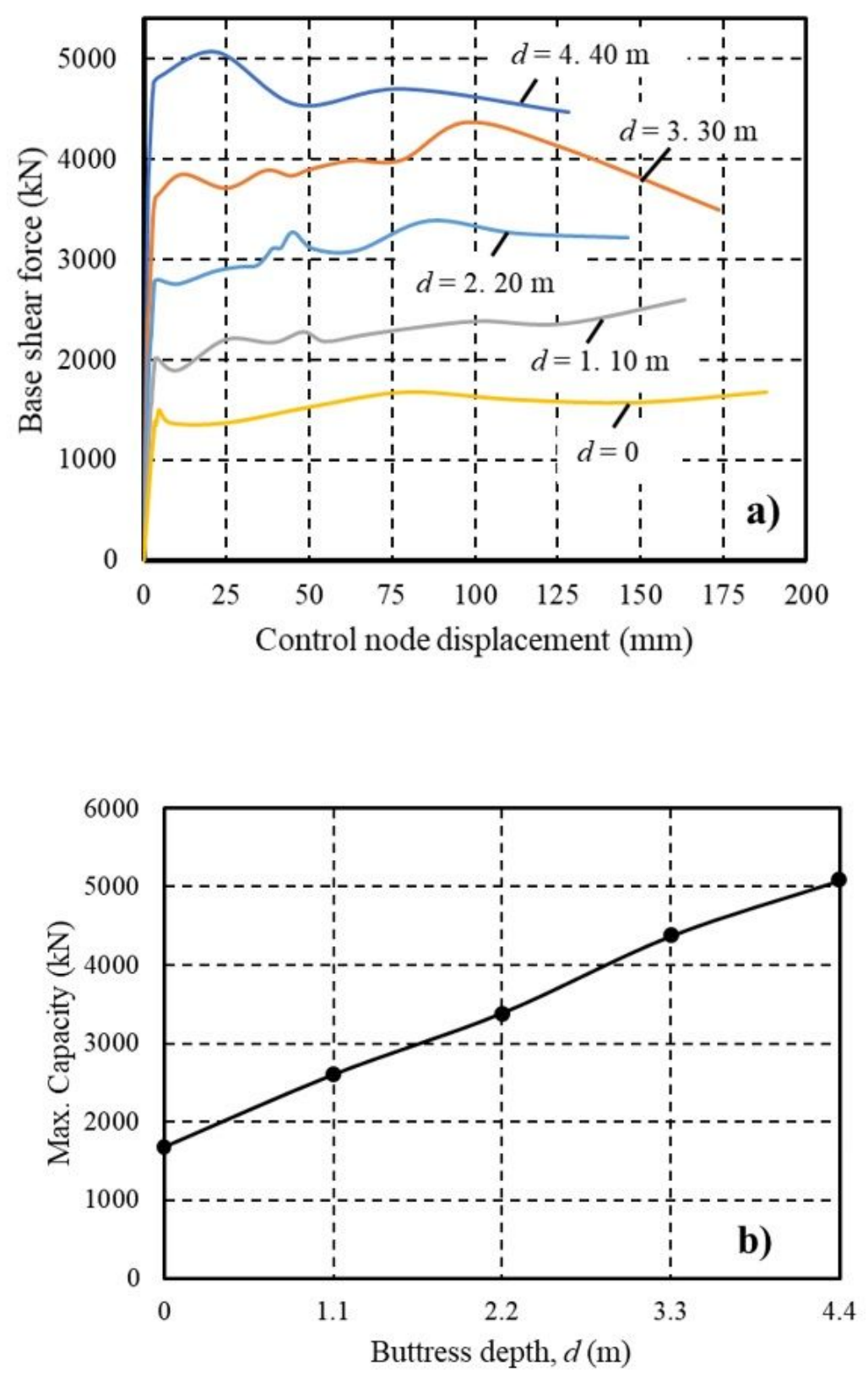

Figure 10

Effect of buttress depth: a) Capacity curves of the rectangular buttressed model for different buttress depths, b) Variation of the maximum capacity of the model with the buttress depth 


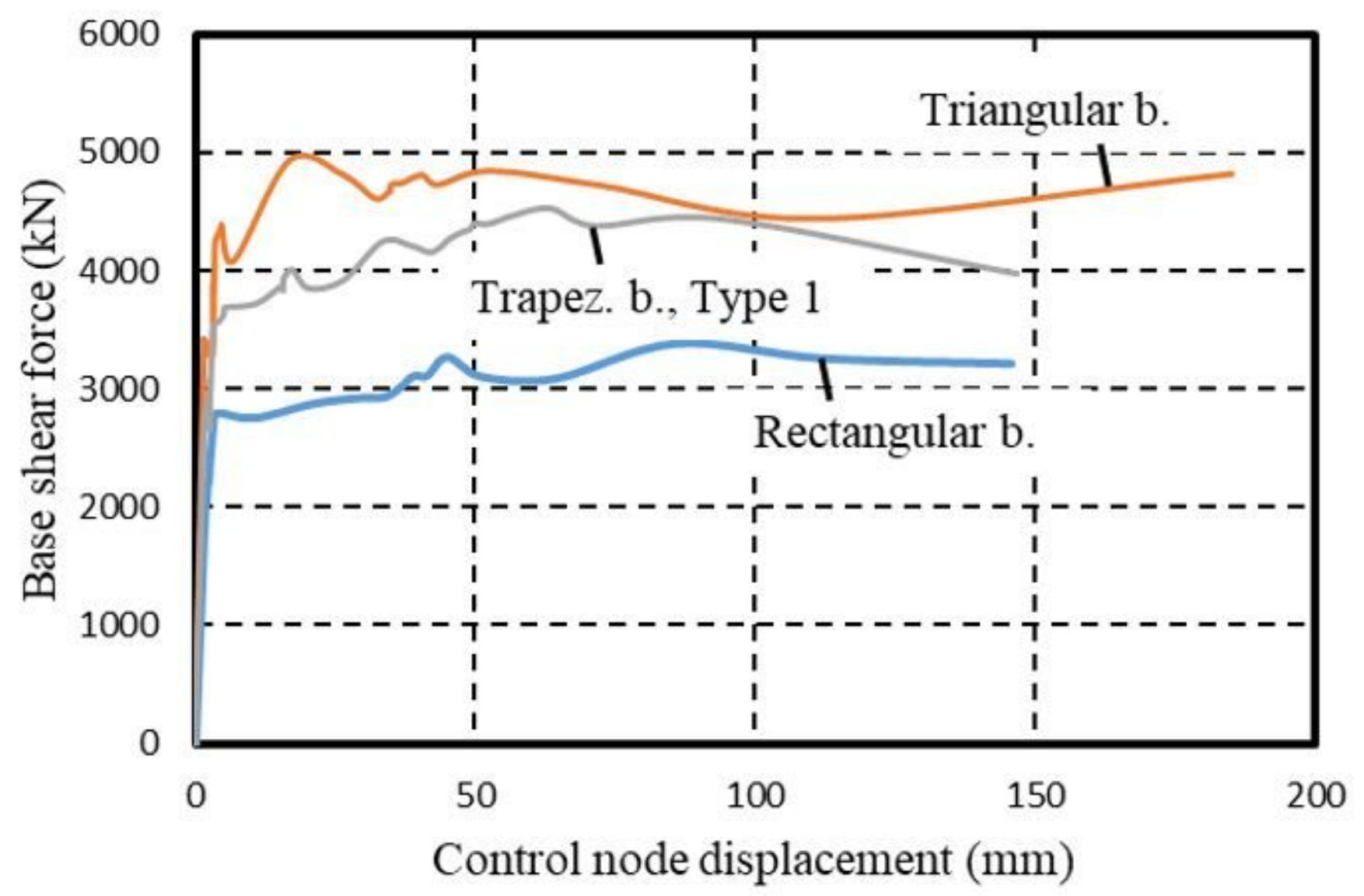

Figure 11

Capacity curves of rectangular, triangular and trapezoidal (Type 1) buttressed models 

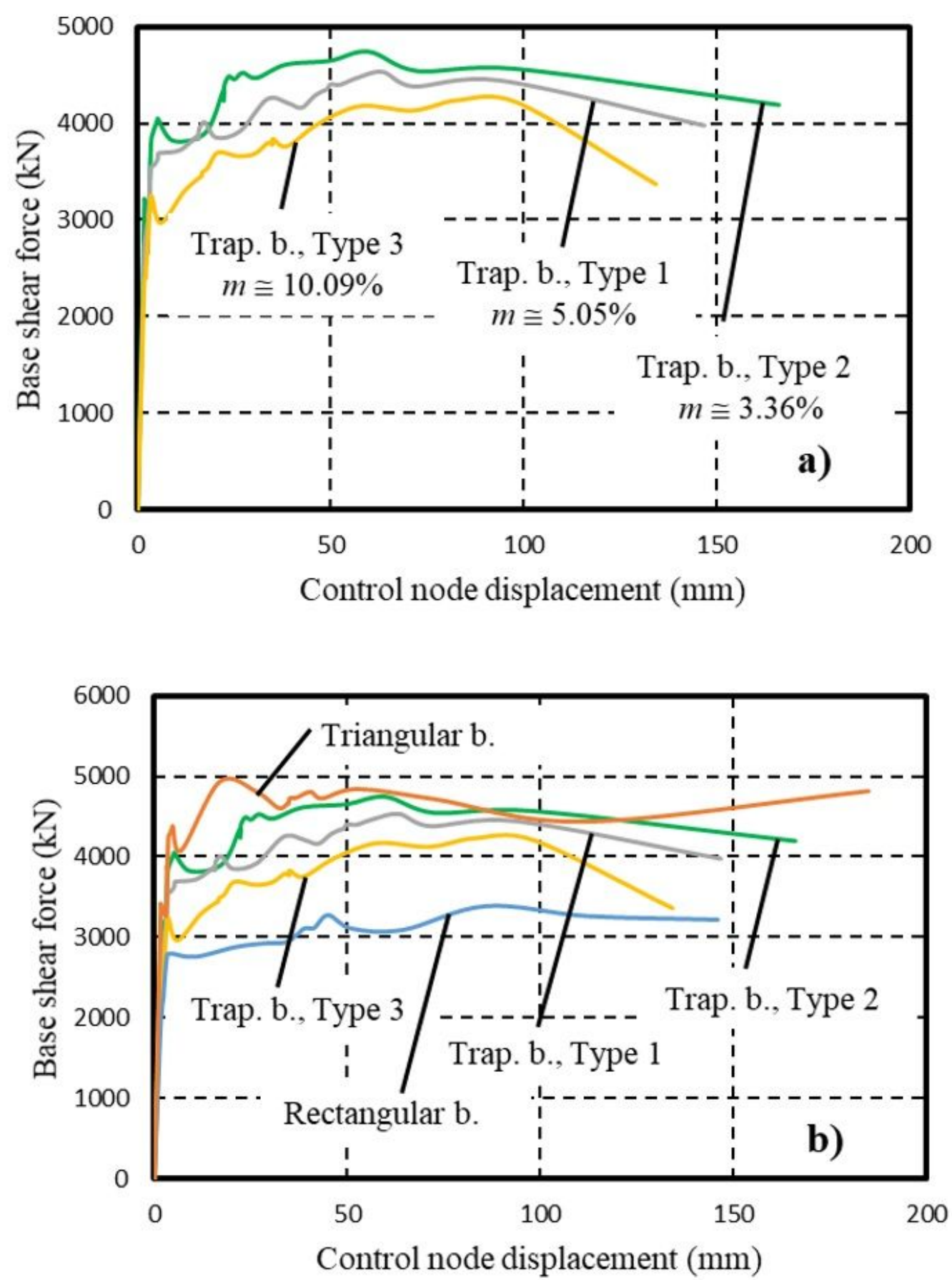

Figure 12

a) Capacity curves of Type1, Type 2 and Type 3 trapezoidal buttressed models (Effect of slope of the trapezoidal buttress on seismic resistance), b) Comparison of the seismic capacities of trapezoidal buttressed models with those of the rectangular and triangular buttressed models 

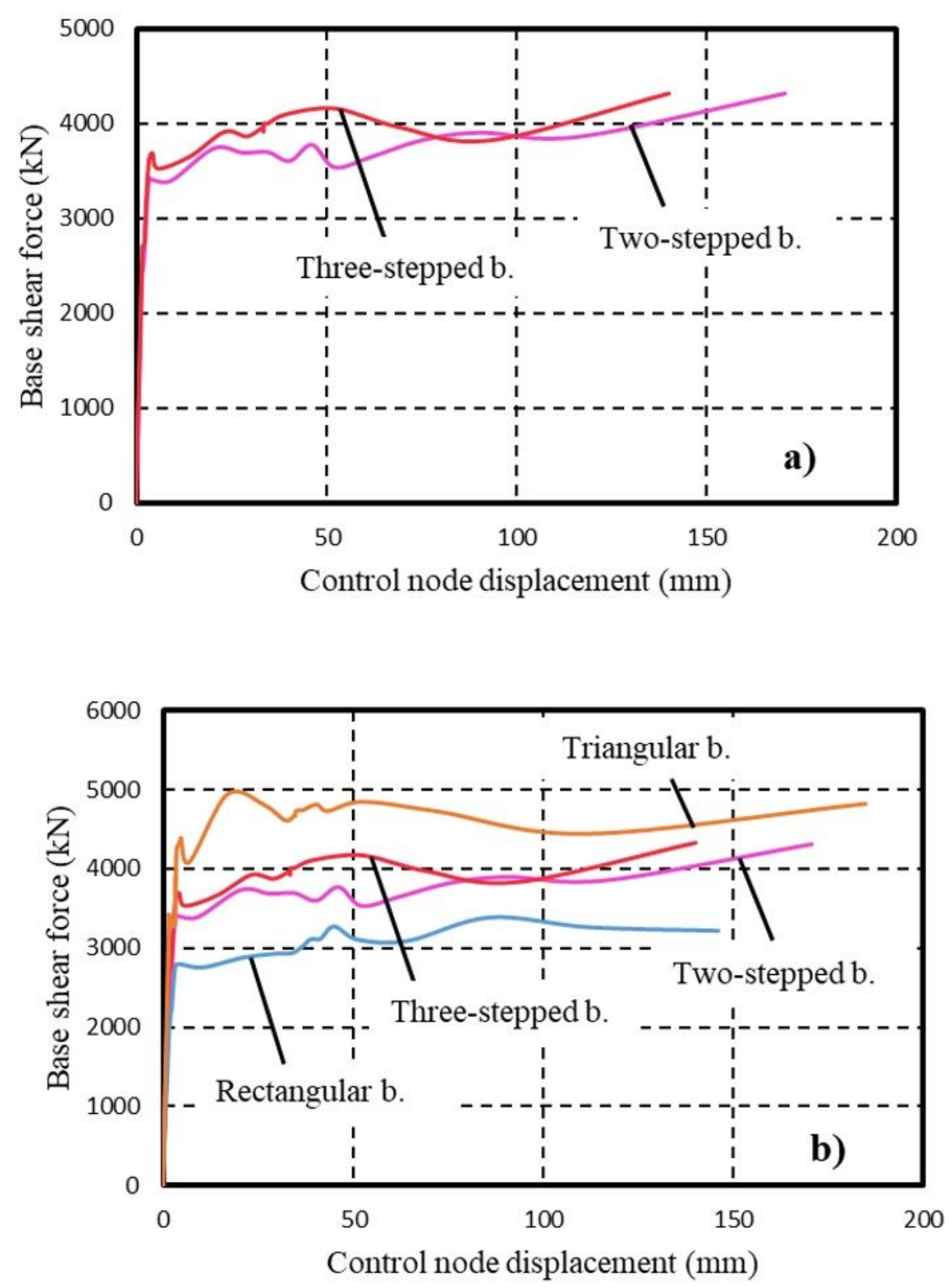

Figure 13

a) Capacity curves of two- and three-stepped buttressed models, b) Comparison of the seismic capacities of stepped buttressed models with those of the rectangular and triangular buttressed models 


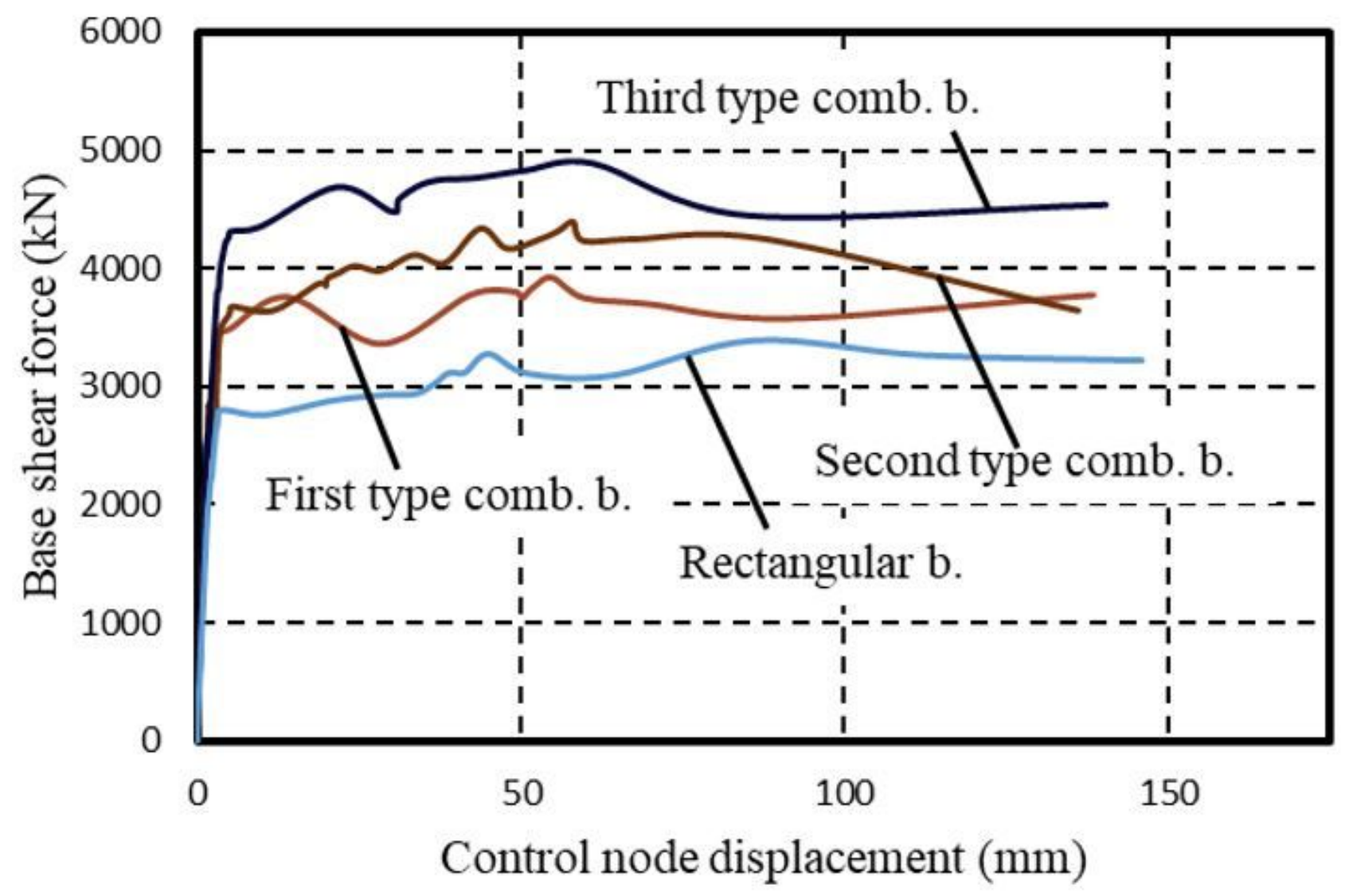

Figure 14

Capacity curves of considered combined buttressed models, and comparison with the capacity curve of the rectangular buttressed model 


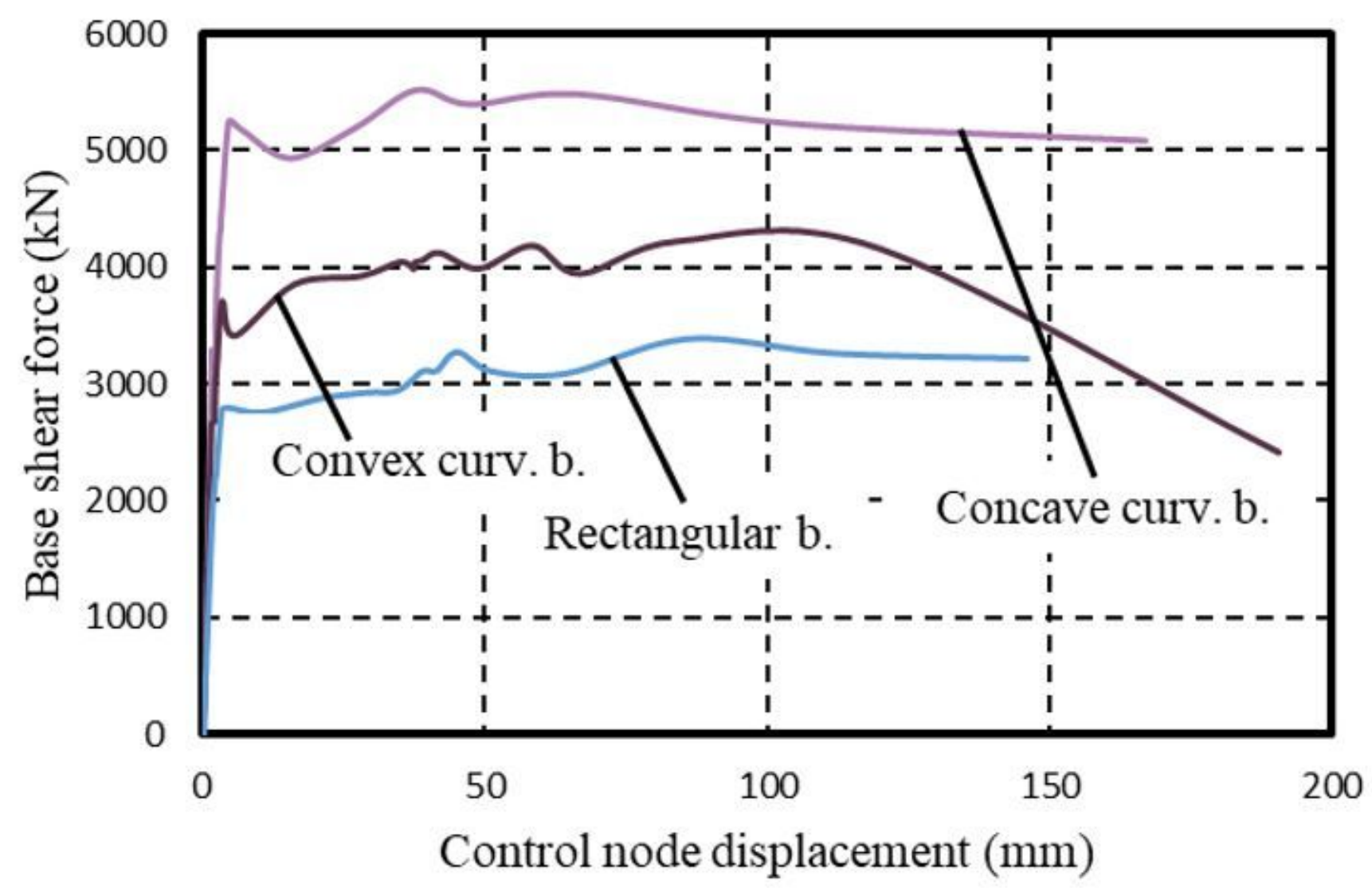

Figure 15

Capacity curves of considered curvilinear buttressed models, and comparison with the capacity curve of the rectangular buttressed model 


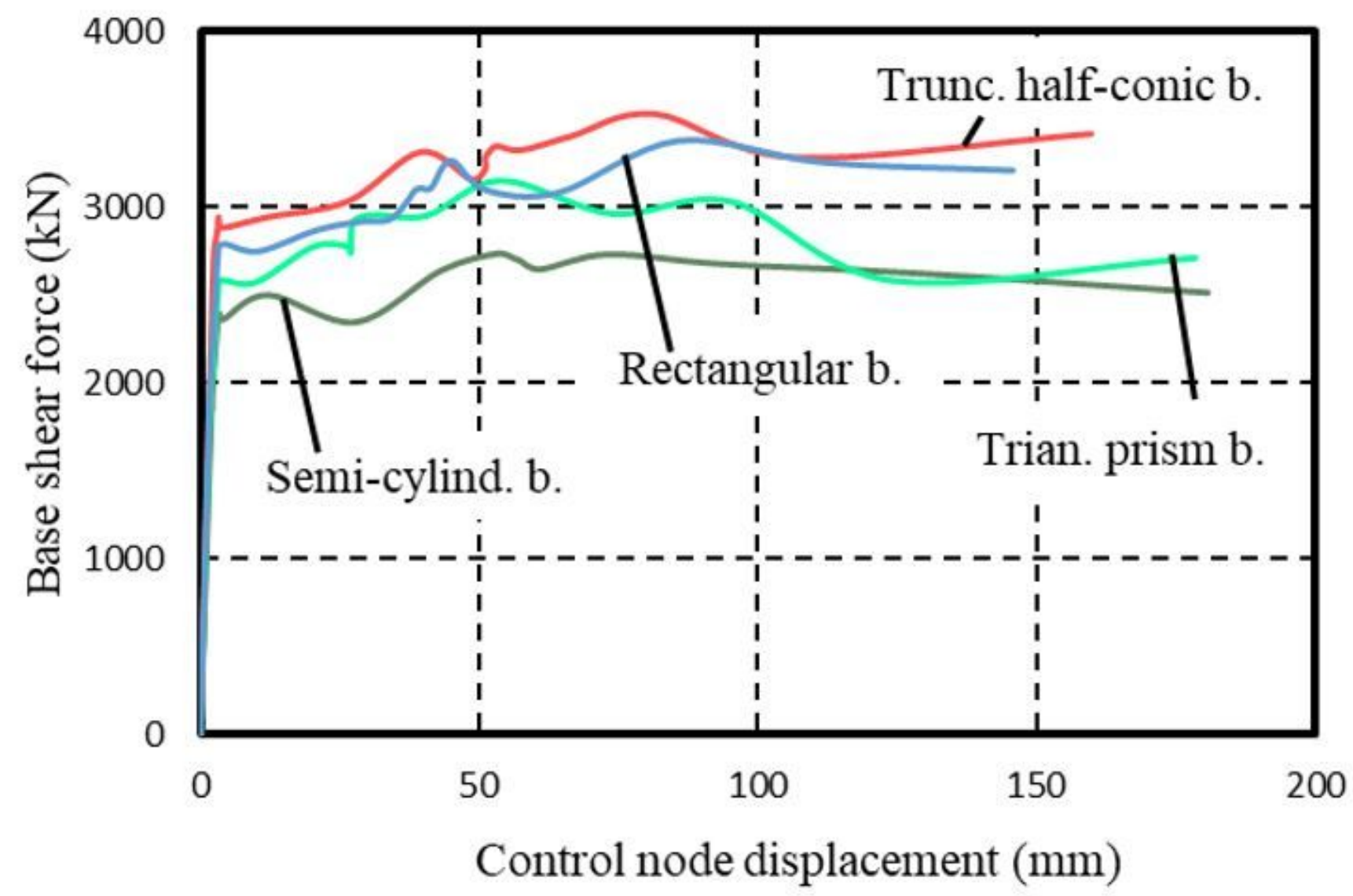

Figure 16

Capacity curves of semi-cylindrical, triangular prism and truncated half-conic buttressed models, and comparison with the capacity curve of the rectangular buttressed model 


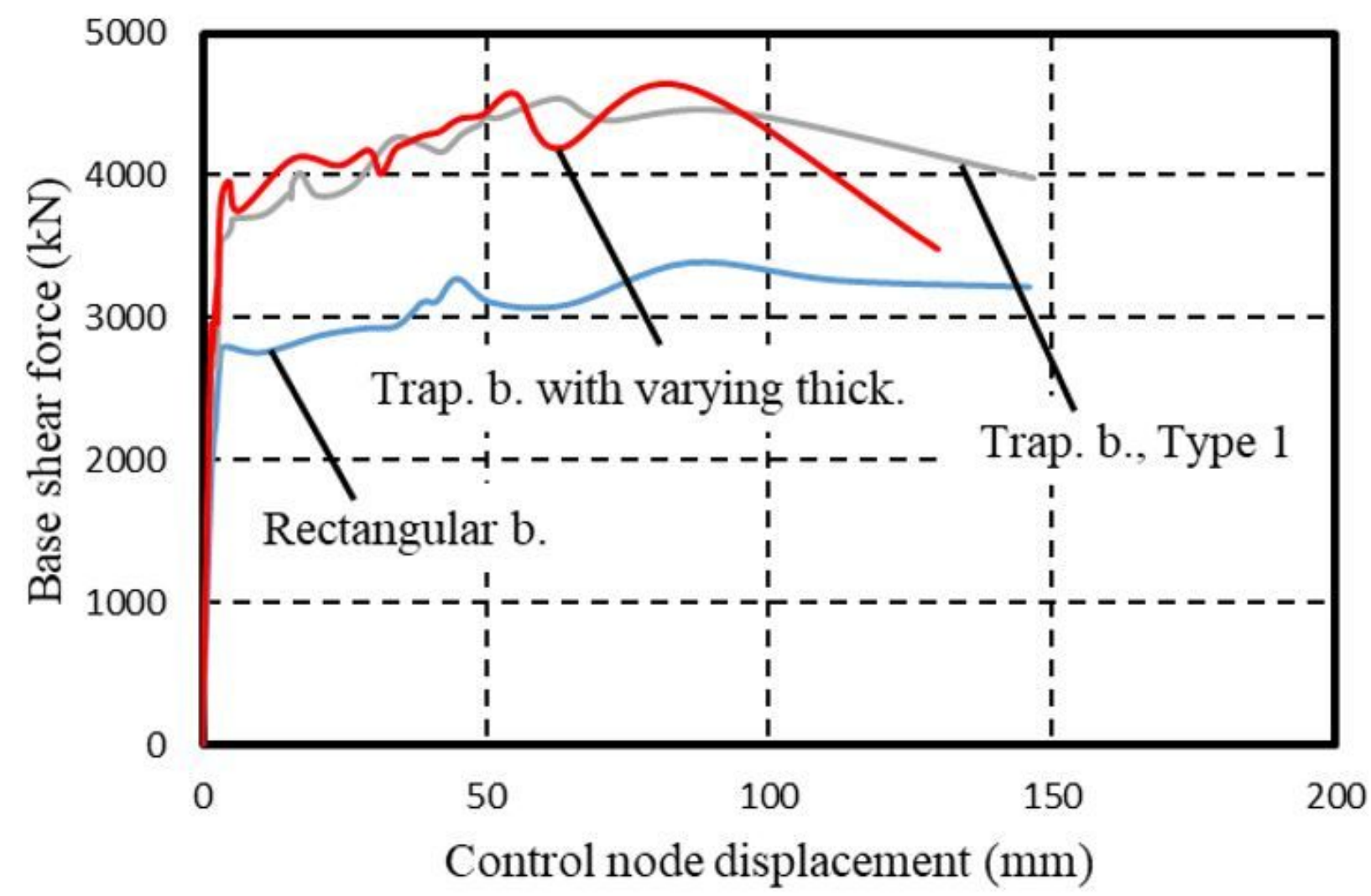

Figure 17

Capacity curve of the model having trapezoidal buttresses with varying thickness, and comparison with the capacity curves of the rectangular and trapezoidal (Type 1) buttressed models 


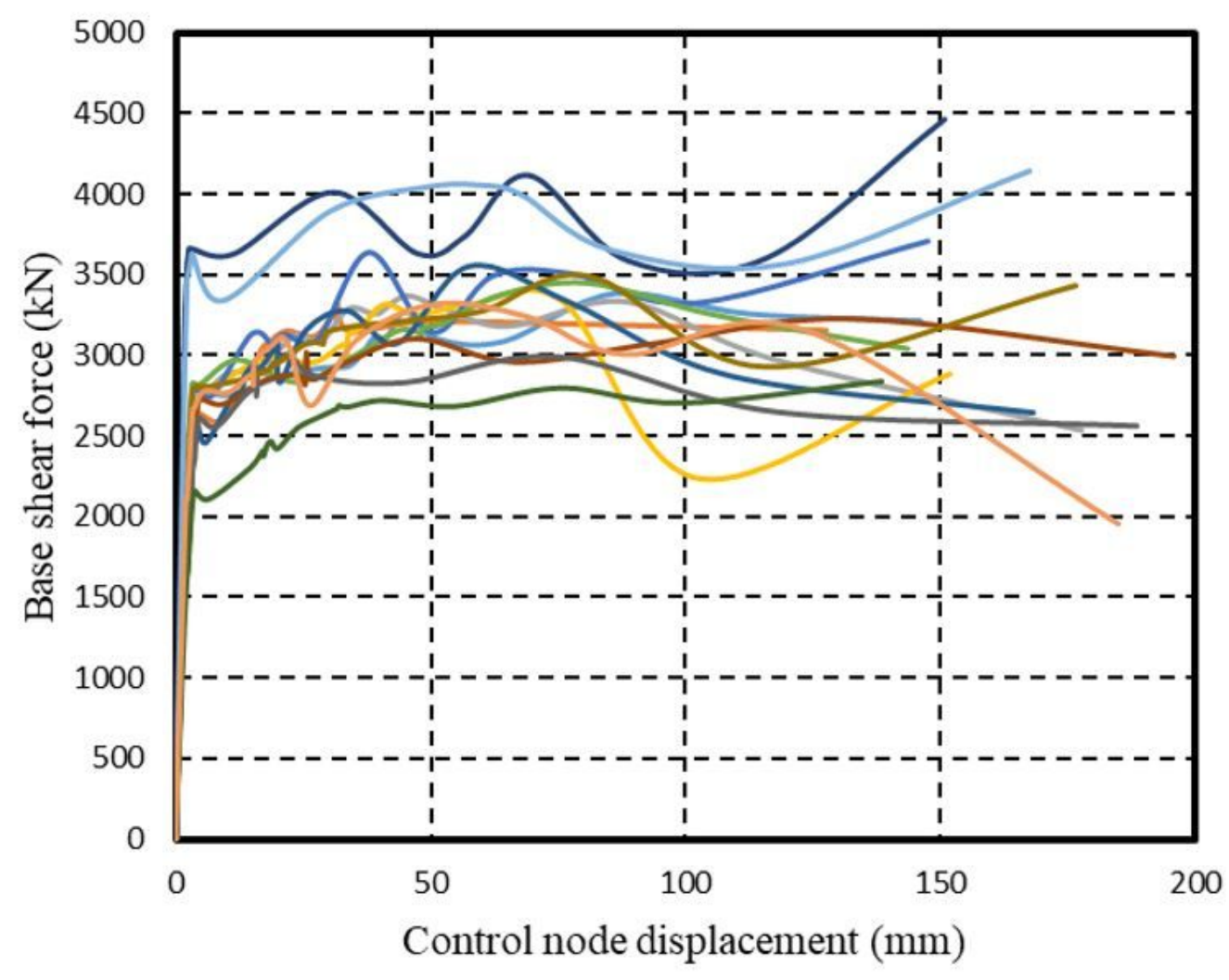

Rectangular b.

Triangular b.

Trapezoidal b.

-Two - stepped b.

Three - stepped b.

First type comb. b.

Second type comb. b.

Third type comb. b.

- Concave curv. b.

Convex curv. b.

$\longrightarrow$ Semi - cylind. b.

Trian. prism. b.

Trunc. half - conic b.

-Trap. b. with vary. thick.

Figure 18

Capacity curves of the models in second group analyses 